\title{
The Role of Virgin Olive Oil Components on the Modulation of Endothelial Function
}

Javier S. Perona, Rosana Cabello-Moruno, Valentina Ruiz-Gutierrez*

Instituto de la Grasa (CSIC). Av. Padre García Tejero, 4. 41012. Seville. Spain.

*Corresponding author.

Running title: Olive oil and endothelial function.

Key-words: virgin olive oil, endothelium, nitric oxide, reactive oxygen species, adhesion molecules. 


\section{Abstract}

The endothelium is involved in many of the processes related to the development of atherosclerosis, which is considered an inflammatory disease. Actually, traditional risk factors for atherosclerosis predispose to endothelial dysfunction, which is manifested as increase in the expression of specific cytokines and adhesion molecules. There is firm evidence supporting the beneficial effects of olive oil, as the most genuine component of the Mediterranean diet. Although the effects of olive oil and other oleic acid-rich dietary oils on atherosclerosis and plasma lipids are well-known, the roles of minor components have been less investigated. Minor components constitute only 1-2\% of virgin olive oil and are comprised of hydrocarbons, polypohenols, tocopherols, sterols, triterpenoids, as well as other components usually found in traces. Despite their low concentration, non-fatty acid constituents may be of importance, since studies comparing monounsaturated dietary oils have reported different effects on cardiovascular disease. Most of these compounds have demonstrated antioxidant, anti-inflammatory and hypolipidemic properties. In the present review we summarize the current knowledge on the effects of these compounds contained in virgin olive oil on vascular dysfunction and the mechanisms by which they modulate endothelial activity. Such mechanisms involve the release of nitric oxide (NO), eicosanoids (protaglandins and leukotrienes) and adhesion molecules, in most cases by activation of nuclear factakB (NFKB) by reactive oxygen species (ROS). 


\section{Endothelial dysfunction in cardiovascular disease}

\subsection{Nature of the atherosclerotic process}

Atherosclerosis remains as the leading cause of death in the developed countries and is on track to become the most common cause of disease-related disability and death by the year $2020[1,2]$. Although several theories have been proposed for the pathogenesis of atherosclerosis, the current trend is to consider it as a response of the vascular wall to a variety of agents and mechanisms, which contribute to the development of the atheromatous plaque [3]. The vascular endothelium is an active and dynamic monolayer of cells, which serves as a semipermeable barrier between blood an tissue [4]. Due to this strategic location it is involved in maintaining homeostasis, by sensing changes in hemodynamic forces and signals and responding to them by releasing bioactive substances $[5,6]$.

Traditional risk factors for atherosclerosis, which is considered an inflammatory disease, predispose to endothelial dysfunction and activation of the endothelium [7]. This activation is manifested as an increase in the expression of specific cytokines and adhesion molecules, such as intracellular adhesion molecule (ICAM-1), vascular cell adhesion molecule (VCAM1) and E-selectin [8,9]. Circulating monocytes are attracted by these molecules and adhered to the endothelium, from which they transmigrate to the subendothelial space. Once within the endothelium, monocytes differentiate into macrophages, which scavenge oxidized LDL and triglyceride-rich lipoproteins (TRL), becoming foam cells and contributing to the formation of the atheroma in the early stages of the atherosclerotic process [7].

\subsection{Function of endothelial cells.}

The endothelium has a major function in thrombotic and coagulant activities, synthesizing several molecules that are released in response to different stimuli [10]. Heparan sulfate, nitric oxide [NO] and prostacyclin are vasodilators, whereas thromboxamrestaglandin endothelin 1 are vasoconstrictors [표]. NO is the primary endothelial-derived relaxing factor playing a pivotal role in vascular reactivity [13]. It inhibits platelet aggregation [13], alters cell adhesion molecule expression and inhibits proliferation of smooth muscle cells [14]. $\mathrm{NO}$ is generated in the endothelial cell by NO synthase (eNOS), which converts the aminoacid L-arginine to NO and L-citrulline. NO diffuses from the endothelial cell to the 
vascular smooth muscle and increases cyclic guanosine monophosphate, thereby causing relaxation of smooth muscle and dilation of the artery.

Endothelial dysfunction occurs early in the development of atherosclerosis, even before the formation of the plaque [15]. Clinical studies have revealed that risk factors for atherosclerosis, such as smoking, hypercholesterolemia, hypertension, diabetes and hyperhomocysteinemia, predispose to endothelial dysfunction [7]. When dysfunctional, the endothelium increases flow disturbances due to improper vasoreactivity. Most importantly, it initiates inflammatory responses by releasing proinflammatory cytokines and chemokines. Thus, it increases leukocyte activation, promotes monocyte adhesion molecule expression and facilitates entry of monocytes and lipoproteins into the subendothelial space [16].

\subsection{Measurement of endothelial function.}

Reliable assessment of endothelial function in humans seems to be of major importance and can be achieved by different approaches. The determination of soluble endothelial markers in blood is the most common and will be discussed later in this review. However, direct measurement of endothelial function would be desirable. Vasodilation can be measured after intra-arterial pharmacologic stimulation with substances that enhance NO release but this method is highly invasive. The most promising non-invasive method is the measurement of the flow-mediated dilation (FMD) in the brachial artery by Doppler ultrasonography. This technique is based on the endothelium sensitivity to shear stress, which elicits NO release and dilation of underlying smooth muscle [17]. Shear stress is caused by hyperemia (induced by cuff inflation and then deflation) and, in these conditions, FMD appears to be mediated mostly by NO $(70 \%)$ and prostacyclin $(30 \%)[17,18]$. Thus, FMD may also serve as an index of NO bioavailability [19]. The endothelial signaling cascade responsible to concert mechanic stimuli into the release of vasodilatory molecules is nor fully known. Although some mechanisms have been suggested, it is probable that it involves phosphorylation of a serine residue of eNOS by shear stress, altering its sensitivity to intracellular calcium levels and hence increasing NO formation [20].

There is ample evidence that FMD is diminished in patients with atherosclerosis and coronary risk factors and that it can detect endothelial dysfunction in hyperlipidemia, hypertension and diabetes [21-23]. FMD has been shown to be decreased after a single high- 
fat meal and postprandial lipemia [24], however there are very scarce data on the effect of olive oil. Vogel et al. [25] found a decrease in FMD after olive oil-rich meals compared with canola oil and salmon, which was attributed to oxidative stress because the decrease in FMD was reduced by the concomitant administration of vitamins $\mathrm{C}$ and $\mathrm{E}$. However, these results should be confirmed with further investigations.

\section{Factors that influence endothelial function}

\subsection{Reactive oxygen species impair the activity of nitric oxide}

There is ample evidence indicating that increased vascular free oxygen levels are the prime mechanism for endothelial dysfunction [6]. ROS may be produced during normal metabolism or after oxidative processes and include superoxide aniban(@hydrogen peroxide $2\left(\mathrm{O}_{k}\right)$ [26]. The contribution of NO and ROS to the vascular tone is inversely proportional to each other and the appearance of one could likely compensate for the absence of the other [27]. The formation of ROS is balanced by a range of antioxidant defenses, but the excess, as in several cardiovascular risk factors like hypercholesterolemia, hypertriglyceridemia or high postprandial triglyceridemia, can overwhelm these systems, leading to oxidative stress.

\subsubsection{Effect of hypercholesterolemia on endothelial dysfunction}

Hypercholesterolemia [28,29], diabetes mellitus [30] and hypertension [31,32] are related to increased production of superoxide anion. This anion reacts rapidly with NO to form peroxynitrite (OONO thus inactivating NO and leading to endothelial dysfunction. ROS can also react with polyunsaturated fatty acids (PUFA) contained in lipoproteins in the vessel wall initiating lipid peroxidation. The hydroperoxides formed in this process can in turn react with NO to form peroxynitrites, inactivating NO and can directly decrease the endothelial synthesis of NO [33]. In addition, altered LDL are not recognized by LDL receptors, which are saturable, and instead are taken up by macrophages through scavenger receptors, not saturable, eventually becoming foam cells. Antioxidants constitute a diverse group of compounds among whose effects includes inhibition of LDL oxidation by both reductions in the concentration and reactivity of oxidants and improved resistance of the particle to them [34]. The antioxidants that have received the most attention are vitamin C (ascorbic acid), vitamin $\mathrm{E}$ ( $\alpha$-tocopherol) and phenolic compounds. In contrast to LDL, HDL provides an 
atheroprotective effect by inhibiting cytokine-induced endothelial cell adhesion molecule expression [35] and by enhancing agonist-induced vasodilation in coronary arteries [36].

\subsubsection{Effect of hypertriglyceridemia on endothelial dysfunction}

There is evidence that hypertriglcyeridemia-induced endothelial dysfunction plays a critical role in this pathology. Traditionally, fasting triglyceride (TG) concentrations have not been considered as an indicator of coronary artery disease (CAD). The metabolic relation between TRL and HDL, the heterogeneity of TRL and the imprecision by which serum TG are determined contribute to the erosion of the relationship between $\operatorname{TG}$ and CAD [37,38]. However, the serum TG concentration is often more strongly correlated with future CAD incidence in multivariate analysis than is serum cholesterol [39]. Considering this evidence and that the TG metabolism also determines the fate of some other lipoproteins, such as LDL or HDL [40], TG seem to have a central role in the pathogenesis of atherosclerosis.

Disorders in TG metabolism may promote atherogenesis by increasing expression of vascular cell adhesion molecules. The concentrations of E-selectine, ICAM-1 and VCAM-1 are increased in the serum of patients with hypertriglyceridemia, independently of other risk factors [41].

\subsubsection{Effect of postprandial triglcyeridemia on endothelial dysfunction}

Postprandial triglyceridemia is also a good predictor of the presence and progression of atherosclerosis [42]. TRL, comprising TG contained in chylomicrons (CM) and VLDL, as well as their remnants, can cross the endothelial barrier and enter the arterial wall [43] and can be taken up by macrophages without need of further oxidation of the particles [44]. It has been suggested that the entry of lipoproteins into the arterial wall is inversely related to the size of the particles, and for that reason, it was thought for many years that TRL were not atherogenic, since they are too large to penetrate the tissue $[45,46]$. However, the TRL remnants formed after the hydrolytic activity of lipoprotein lipase (LPL) and endothelial lipase (EL) can enter the arterial intima and thus, be more atherogenic than their nascent precursors [47]. 
In vitro studies of endothelial cells reported that LPL-derived TRL remnants isolated from hypretriglyceridemic subjects have the ability of disrupt endothelial integrity $[48,49]$. It has been shown that remnant-like lipoprotein particles (RLPs) have a causative role in endothelial vasomotor dysfunction in human coronary arteries and that RLPs directly induced endothelial dysfunction in the isolated rabbit aorta [50,51]. In fact, TRL and their remnants stimulate endothelial cell plasminogen activator inhibitor-1 [PAI-1] production [52], which is a marker of endothelial dysfunction, and cause a profound depression of fibrinolytic activity [53]. TRL remnants also promote an enhanced thrombogenic tendency by increasing circulating factor VII levels [54].

In addition, it has been reported that monocyte adhesion to endothelial surface is enhanced by TRL $[55,56]$. CM preparations obtained from human plasma $4 \mathrm{~h}$ after a standard fatcontaining meal, were shown to up-regulate the expression of E-selectin and VCAM-1. Interestingly, TRL did not require LPL to promote the expression of adhesion molecules, suggesting that these particles may be pro-inflammatory themselves independently of their ability to release fatty acids [57]. Doi et al. [56] confirmed the up-regulation of protein and mRNA expression of these adhesion molecules when endothelial cells were incubated with TRL obtained from hypertriglyceridemic patients and they extended it to ICAM-1 and tissue factor (TF).

The oxidative mechanism can at least partially explain the adverse effects of TRL on endothelial cell function. TRL accumulation in plasma leads to increased oxidative stress and decreased NO availability as it is associated with increase of vascular superoxide anion production [58]. In their study, Doi et al. [56] observed increased cellular oxidant levels in the endothelial cell incubation medium containing TRL and that co-incubationtactupherol decreased the concentrations of ICAM-1 and VCAM-1.

Hydrolytic enzymes, such as LPL and EL may be directly implicated in endothelial dysfunction, as their synthesis is up-regulated in early atherosclerosis [59]. Apart from smooth muscle cells, LPL is produced by monocytes and macrophages [69-đBere is evidence that LPL activity can enhance the retention of LDL and VLDL to the arterial wall $[64,65]$, but also it facilitates proteoglycan-mediated monocyte adhesion to the endothelium [66] Actually, inflammatory cytokines, such as Telland IL-13 can up-regulate endothelial derived LPL mRNA [67]. In contrast to LPL, EL is synthesized in the endothelium and has a 
primary phospholipase activity [68]. However, its mRNA expression is also increased in endothelial cells by TNFor and IL-1 [67]. The upregulation of these enzymes is thought to be mediated via the nuclear factoB (NF KB) pathway [69]. NFKB can be activated by a number of stimuli, including lipids and ROS. These stimuli cause the phosphorilatiBn of I and subsequent proteolytic degradation of this inhibitor subunit, allawirtg Nanslocate into de nucleus, where it binds to recognition sequences in DNA in order to induce gene expression [70].

\subsection{Beneficial and adverse effects of dietary fatty acids.}

It has been postulated that as energy needs are increased during acute inflammation, lipolytic enzymes are up-regulated as a way of generating free fatty acids from circulating lipoproteins to be used by the tissues, including the endothelium. The increase in free fatty acid concentrations in the endothelium has been shown to decrease endothelial NO bioactivity, due to both superoxide generation and reduction in eNOS activity [71,72]. In vitro studies suggest that PUFA are more pro-inflammatory than monounsaturated (MUFA) and saturated (SFA) fatty acids [73]. In fact, linoleic acid $(18: 2, n-6)$ has greater capacity to induce oxidative and inflammatory stress than other fatty acids. Incubation of this fatty acid with endothelial cells promotes NHB activation and transcriptional activity, being this effect is attenuated by vitamin E [74]. Additionally, exposure of endothelial cells to linoleic acid can lead to production of cytokines, such as IL-6 and IL-8 [75], which are involved in the initiation and progression of atherosclerosis [76,77].

Conversely, n-3 PUFA are believed to exert an endothelial protective effect. Particularly, docosahexaenoic acid (22:6, n-3; DHA) decreases expression of VCAM-1 on the vascular endothelium and monocyte adhesion [78-80] and eicosapentaenoic acid (20:4, n-3; EPA) increases NO production. Although these results from in vitro studies are promising, in vivo studies were more controversial. Abe et al. [41] found no reduction in soluble adhesion molecules after 6 weeks in patients receiving n-3 fatty acids but did find reductions in ICAM1 and E-selectin after 7 months. Seljeflot et al. [81] supplemented male smokers with $n-3$ fatty acids for 6 weeks finding reductions in pro-thrombogenic von Wilebrand factor but increase in VCAM-1 and E-selectin. Their results were corroborated by Johansen et al. [82]. 
Among the key inflammatory mediators released by the endothelium are the eicosanoids derived from the n-6 PUFA arachidonic acid (20:4, n-6; AA). Prostaglandin E2 (B)Gan cause pain and vasodilation and leukotriene B4 ( neutrophils. They are formed from AA via the cyclooxygenase (COX) and 5-lipooxygenase (LOX) pathways, respectively. However, EPA is also a potential COX substrate and can compete with $A A$ for this enzyme leading to formation of $B_{3}$ Glithich is synthesized with very low efficiency [83]. EPA is also substrate for LOX forming LTB 5 , with less inflammatory activity compared to $14[\mathbb{B} 4,85]$. Thus, increasing the $n-3$ content in the diet, the balance of the eicosanoids produced can be shifted to a less inflammatory mixture.

\section{Evidences of the benefits of olive oil on cardiovascular disease}

A number of epidemiological studies developed in different countries constitute a firm and reliable experimental base supporting the beneficial effects of the Mediterranean diet, rich in olive oil, in regard to the reduction of CAD [86].

The Seven Countries Study, initiated by Ancel Keys in 1970 [87], was designed to investigate relationships between diet and CAD comparing different populations. The results of this study showed that the population of the Mediterranean island of Crete had the lowest rates of CAD and cancer, concluding that the cause might be the low saturated fat and high oleic acid intake, in terms of olive oil, of the Mediterranean diet. Subsequently, the Lyon Diet Heart Study [88] developed on patients recovering from a myocardial infarction, was the first clinical evidence in support of the health benefits of a Mediterranean-style diet, similar to that of Crete. The protective effects were ascribed to higher intakes of oleic acidlimiodenic acid $(18: 3, n-3)$ and lower intakes of saturated fatty acids and linoleic acid (18:2, n-6). Trichopoulou et al. [89], demonstrated that the adherence to a Mediterranean diet reduced mortality from cancer and coronary heart disease in a Greek population of more than 22,000 individuals. These results were more recently confirmed in subjects diagnosed of CHD [90].

Cumulative evidence suggests that MUFA may be key components in the protective role of the Mediterranean Diet [91]. In fact, MUFA are believed to be as effective as n-6 PUFA at lowering total and LDL-cholesterol when replacing saturated fatty acids, as supported by two meta-analyses [92,93]. In addition, it has been reported that a controlled olive oil-based diet 
can even lower plasma triacylglycerol levels [94], although there is some controversy in this regard $[95,98]$.

It is probable that arterial hypertension resulted to be "quantitatively" the most important risk factor for CHD, due to its repercussion on cardiovascular mortality [99]. Diets enriched in n-3 PUFA are known to reduce blood pressure in humans $[100,101]$ and in Spontaneously Hypertensive Rats (SHR) [102], which has been related to increased synthesis of series n-3 eicosanoids, with a stronger vasodilator effect than their series $n-6$ homologous [103]. However, there is increasing evidence showing that olive oil reduces systolic and diastolic blood pressure in normotensive $[14,105]$ and hypertensive individuals [106]. Recently, another study including participants that had never received a diagnosis of hypertension confirmed these results. It concluded that the Mediterranean diet is inversely associated with arterial blood pressure and that olive oil intake, per se, is inversely associated with both systolic and diastolic blood pressure [107]. The modification in blood pressure by dietary olive oil has been related to changes in the fatty acid composition of cell membrane, which affects its functionality $[106,108]$.

Oxidative modification of LDL is an important determinant in the development of atherosclerosis, as it accelerates the uptake of LDL by macrophages, which is the beginning of formation of a fatty streak. LDL may be protected against attacks of free radicals by antioxidants in plasma and in the particle itself. Lipoproteins rich in MUFA after long-term consumption of olive oil have been shown to be less susceptible to oxidation compared to particles enriched in PUFA [109-113].

An increasing number of studies point out that the content of oleic acid alone can not fully explain the impact on health of olive oil. This conclusion has been drawn from studies comparing the effects of diets enriched in different monounsaturated oils [114], among which VOO and high oleic sunflower oil (HOSO) have been most widely used.

Unlike VOO, HOSO was not able to reduce the blood pressure, in hypertensive patients [106]. Further studies in humans revealed that this differential effect was related to the composition and functionality of the cell membrane of hypertensive patients $[106,115]$. In SHR, VOO and HOSO yield to different liver, adipose tissue and myocardium lipid composition [116-118] and vascular reactivity [119]. These differences may be consequence 
of a differential incorporation of the components of VOO and HOSO into TRL [120-122]. Actually, postprandial lipoproteins obtained after ingestion of VOO or HOSO are differentially incorporated into vascular cells [123], from which release of eicosanoid substances is also affected [124]. Furthermore, it has been reported that LDL from olive oilfed rats were more resistant to oxidation in vitro than those isolated from plasma of trioleinfed rats [125]. The differential effects of different oleic acid-rich oils on LDL oxidation were confirmed in ten normolipidemic subjects by Nicolaiew et al., [126] after administration of VOO or HOSO. These data support the idea that the protective effects of olive oil against CAD must not be attributed exclusively to oleic acid, but to some other components of the oil.

Among the differential characteristics of VOO, the quantitatively most important is the TG molecular species composition. Compared to HOSO, which contains mainly triolein, VOO contains also important amounts of dioleoy-palmitoyl-glycerol. In much lower concentrations, but with growing evidence of important biological effects, minor components of olive oil can be also used to differentiate this oil from others.

\section{Chemical composition of olive oil}

In contrast to most dietary oils, which are obtained from the seeds of the plants by means of solvent extraction, and refined before being edible, olive oil is obtained from the whole fruit of Olea Europaea L, only by physical pressure. This procedure makes olive oil unique, since some compounds that cannot be found in other dietary oils are transferred from the leaves and skin of the fruit to the oil.

Olive oil can be classified into two fractions from a quantitative point of view. The major fraction constitutes $98-99 \%$ of the oil and it is mainly composed of saponifiable glyceridic compounds as triacylglycerols (TG). The abundance of oleic acid is peculiar to olive oil and ranges from $60-84 \%$ of total fatty acids in TG, while linoleic acid, the major essential fatty acid and the most abundant polyunsaturated acid in our diet, is present in concentrations between $3-21 \%$.

Minor compounds account for the rest 1-2\%, comprising unsaponifiable compounds, phenolics and waxes, and despite of being a little proportion, they confer important biologic activities. The minor compounds of VOO, classified in growing order of polarity after developed by thin-layer chromatography are: hydrocarbons, tocopherols, fatty alcohols, 4- 
methylesterols, sterols, triterpenic dialcohols, polar-coloured pigments and phenolic compounds [127].

One of the greatest differences between VOO and the rest of edible oils is the composition in hydrocarbons [128]. Among them, the most important is squalene [129], a polyunsaturated triterpene that appears at high concentration and makes up $60-75 \%$ of the unsaponifiable fraction of the olive oil [130], and it is a precursor in the biosynthesis of cholesterol and steroid hormones $\beta$-carotene is also found within this group, a triterpenic polyunsaturated hydrocarbon which plays an important role as precursor of vitamin A and, along with lycopene, conferring the yellowish colour to the oil. The analysis of the sterol fraction is of importance because it helps to the characterisation of the species from which the oil has been extracted [131]. The main sterol found in virgin olive oil is $\beta$-sitosterol [95\%] but campesterol, $\Delta-7$ stigmastenol, stigmasterol, spinasterol and avenasterol are also present. VOO contains $\alpha, \beta, \gamma$ and $\Delta$-tocopherols, but-tocopherol typically accounts for more than $85 \%$ of total tocopherols. Triterpenic dialcohols and acids, from the skin of the fruit and from the leaves are incorporated in second pressing oil and the final concentration is higher than in VOO. The main dialcohol is known as erythrodiol, which in some cases, is accompanied by another triterpenic-tetracyclic diol identified as uvaol. Among acids, oleanolic and maslinic have recently revealed some pharmacological properties, which will be discussed below.

Phenolic compounds are rarely determined in routine analysis because of their solubility in water and diluted bleach, what explains their absence from both unsaponifiable and glyceridic fractions. These substances constitute the 'polar fraction' in VOO and underlay its exceptional thermal stability [132-134], contribute to its characteristic flavour and taste, and prevent its autooxidation, contributing to the resistance of VOO to oxidative rancidity [135]. Phenolic compounds have emerged as potent antioxidants present in VOO. Among these compounds, oleuropein itself and its derivatives, tyrosol and hydroxytyrosol, have been reported to have a protective role against LDL oxidation in vitro, equivalent to vitamin $\mathrm{E}$ [136]. Although it has been demonstrated that VoO phenolics are dose-dependently absorbed in humans [137], in plasma they are mostly present as conjugates of glucuronic acid. The in vivo antioxidant effect of VOO phenolics and the antioxidant capacity of the glucuronidates are scarce and controversial. However, interventional studies administrating increasing doses 
of phenolic compounds in VOO have reported reduced oxidative status in healthy $[138,139]$ and dyslipemic subjects [140].

5. Effects of the components of olive oil on the endothelial function

Very few studies have addressed the effects of long-term olive oil consumption on the endothelial function. Mediterranean diet, rich in olive oil, has been shown to improve endothelial function in diabetic [141] and hypercholesterolemic patients [142], as assessed by measuring endothelium-dependent vasoreactivity. Fuentes et al., [142] also observed a reduction in the plasma levels of P-selectin. In a randomized crossover trial, Ros et al. [143] confirmed the improvement on endothelial function in 22 hypercholesterolemic subjects receiving a Mediterranean diet. However, the results were more evident when part of the dietary olive oil was replaced with walnuts. Sondergaard et al., [144] observed a greater improvement in flow-mediated vasodilation (FMD) in patients receiving fluvastatin when they were advised of following a Mediterranean diet. Esposito et al. [145] carried out a randomized trial among 180 subjects with metabolic syndrome, who were instructed to follow a Mediterranean-style diet, including olive oil. After two year follow-up, they observed improved endothelial function as a measure of blood pressure and platelet aggregation response to L-arginine, the natural precursor of nitric oxide. They also reported a significant reduction of markers of systemic vascular inflammation, such as C-reactive protein and interleukins 6 (IL-6), 7 (IL-7) and 18 (IL-18), apart from total and LDL-cholesterol. However, the mechanisms by which dietary olive oil elicits these effects and which are the actual components of the oil responsible for the effects are poorly elucidated. Below, we show the current knowledge on the effects of the components of olive oil on endothelial activation. A graphic summary of the mechanisms is depicted on Figure 1.

\subsection{Effects of major components of olive oil on endothelial function}

\subsubsection{Effects of oleic acid}

Oleic acid, the main fatty acid contained in olive oil, accounts for about $29 \%$ of the daily caloric intake in some Mediterranean countries. Recent studies testing the role of different unsaturated fatty acids in endothelial cell activation and injury, suggest that oleic acid does 
not activate endothelial cells confirming its benefits on early events in atherosclerosis compared with other unsaturated fatty acids [146]. Carluccio et al. [147] reported that plasma concentration of oleate under conditions of high olive oil consumption are likely to be fully in the range of concentrations exerting biological effects in our system, likely between 10 and $100 \mu \mathrm{mol} / \mathrm{L}$.

Tsimikas et al. [148] assessed the proinflammatory potential of LDL isolated from Greek subjects consuming a diet naturally rich in olive oil. Oleic acid content in LDL was significantly higher in the Greek compared Americans and was inversely correlated with the extent of in vitro LDL oxidation and the induction of monocyte adhesion by mildly oxidized LDL. To confirm that dietary fatty acids influence the proinflammatory properties of mildly oxidized LDL, native LDL were also isolated from American subjects after consumption of a liquid diet supplemented with either oleic or linoleic acid. The oleic acid-supplemented group had higher oleic and lower linoleic acid content in LDL than the linoleate-supplemented group. When exposed to oxidative stress, the LDL enriched in oleic acid promoted less monocyte chemotaxis and reduced monocyte adhesion, showing a strong negative correlation between oleic acid LDL content and monocyte adhesion. This study demonstrated that the level of dietary enrichment with oleic acid necessary to obtain these benefits is realistic and readily achieved by using diets currently in use in Mediterranean countries. Also, this study suggested that LDL enriched with oleic acid and reduced in PUFA may be less easily converted to a proinflammatory, minimally modified LDL, which has the ability to enhance monocyte chemotaxis and adhesion.

The main challenge after these results is to discover which are the underlying mechanisms implicated in oleic acid beneficial effects. Initially, Tsimikas et al. [148] explained the mechanism by which oleic-acid enriched diets decreased lipoprotein susceptibility to oxidation, presumably, as a result of the decreased linoleic acid content within lipoprotein. However, previous experiments with liposomes progressively enriched in oleic acid but with constant amounts of linoleic acid, showed that particles with higher oleic acid concentration were less susceptible to oxidation, and monocyte chemotaxis and adhesion were nearly completed inhibited when exposed to mild oxidative stress, suggesting that oleic acid may have an additional independent mechanism of action [149]. 
Studies on endothelial cells in vitro have shown that the main dietary PUFA and oleic acid may prevent endothelium activation either by inhibiting the expression of adhesion molecules or by improving the NO production [150]. Supplementation of endothelial cells with oleic acid in vitro reduces endothelial cell sensitivity to oxidants, creating a reduced prooxidant environment as a consequence of reduced intracellular ROS [151,152]. In this environment, oleate reduces the activation and mRNA expression ofBland AP-1, thereby interfering with the endothelial expression of adhesion molecules for circulating monocytes and contributing to a direct vascular atheroprotective effect [153-156]. Additionally, cellular treatment with this fatty acid protects endothelial cells against cytokine-induced VCAM-1, ICAM-1, or E-selectin overexpression [147].

This condition might occur by two mechanisms: reduced enzymatic production of ROS or increased scavenging after their production. It has been suggested that the inhibitory potency of unsaturated fatty acids is directly proportional to their number of double bonds $[153,156]$. According to this, DHA, with 6 double bonds would be 6 times more potent than oleic acid. However, addition to oleic acid to the culture medium significantly increases the unsaturation index [147], probably through selective displacement of SFA, but not PUFA, in cell membrane phospholipids, with a consequent modulation of gene expression for molecules involved in monocyte recruitment [153]. Actually, the kinetics of VCAM-1 inhibition by oleic acid resembles that of DHA. Similarly to what has been previously shown for DHA, the effect is totally independent of the stimulus used: cytokines acting on totally different receptors, such as IL-1, TNFe, IL-4, or LPS, and inducing different responses [157].

Oxidation of fatty acids might help scavenging of ROS, thus reducing the formation of superoxides that can be dismutated to hydrogen peroxide, which is in turn responsible for NF$\kappa B$ activation [158,159]. Therefore, an alteration of hydrogen peroxide metabolism in vascular cells may contribute to the ability of fatty acids to modulate cellular oxidant susceptibility [160].

Experiments with porcine artery endothelial cells (PAEC) supplemented with oleic acid and exposed to oxidant conditions by means of hydrogen peroxide treatment showed an attenuated increase in intracellular hydrogen peroxide [161]. The consequence was an increase in resistance to derangements caused by oxidized LDL and a reduction in oxidant mediated 
dysfunction [160,162]. Massaro et al. [163] showed that incubating of oleate with cytokinestimulated endothelial cells, prevents the depletion of glutathione (GSH) and partially prevents stimuli-induced increase of intracellular ROS. This occurred without any change in the activity of GSH-related antioxidant enzymes, superoxide dismutase and catalase. These authors suggested that oleate may exert direct vascular atheroprotective effects by inhibiting endothelial activation through quenching of ROS. In contrast, incubation with linoleic and stearic acids reduces GHS levels and increasexBIf146,155]. Additionally, coincubation of linoleic acid with TNFe doubled the production of IL- 6 compared with बतNFlone. This was concomitant to an increment in the content of arachidonic acid in membrane phosphatidylethanolamine.

In contrast with these results, other authors have suggested negative effects of circulating nonesterified fatty acids like oleic acid in diabetic patients. Experiments with cultured rat aortic smooth cells maintained in media containing oleic acid concentrations similar to those in diabetic patients showed a significant increase in endothelin-1 receptor amount suggesting that it may contribute to the acceleration of atherosclerosis in diabetic patients. $[164,165]$.

5.2Effects of minor components of olive oil on endothelial function

\subsubsection{Effects of olive oil phenolic compounds}

The major phenolic compounds in olive oil, oleuropein, hydroxytyrosol and tyrosol; are strong antioxidants and radical scavengers [166], which can help to revert the imbalance between increased oxidative stress and impaired antioxidant defence that affects endothelial function, and therefore contributes to atherosclerotic disease progression.

Associations between oxidative stress and impaired endothelial function have been demonstrated in experimental animal models of atherosclerosis, hypertension, hypercholesterolemia and diabetes [167-169]. Reduced bioavailability of NO in a setting of increased superoxide anion levels seems to be constant biological changes that occur in the vessel wall under these conditions [170]. In fact, it has been described that endothelial vasomotor dysfunction could be reversed in these kind of patients by the administration of agents capable to scavenging ROS [171-174]. 
A number of papers have reported in vitro experiments evaluating and confirming the antioxidant activities and the scavenging potencies of olive oil and its isolated constituents [175-179].

The low unsaturation of olive oil fatty acids, in addition to water soluble antioxidant protection in the form of phenolic compounds favourably influences a reduced susceptibility to oxidation of olive oil-derived lipoproteins [180]. Recently, it has been reported that an olive oil intake of $25 \mathrm{~mL}$ in a single dose does not promote exacerbated hypertriglyceridemia or hyperglycemia, which are linked to postprandial oxidative stress. These authors found a postprandial increase of both tyrosol and hydroxytyrosol, two phenolic compounds frequently used as markers of olive oil intake. The increased concentration of these phenols in plasma may be related to the reduced oxidative stress, since their increase was concomitant to a postprandial decrease in plasma oxidized LDL.

Oleuropein and hydroxytyrosol are potent scavengers of ROS and superoxide anion in neutrophils [177,179]. Saija et al. [175] hypothesized that whereas hydroxytyrosol can serve as scavenger of aqueous peroxyl radicals near the membrane surface, oleuropein acts also as scavenger of chain-propagating lipid peroxyl radicals within the membranes. Additionally, oleuropein has been shown to increase NO production from LPS-stimulated mouse macrophages [181] and to possess a tonic effect toward the inducible form of NO synthase (iNOS). Tuck et al. [166], reported that these two phenolic compounds, as well as caffeic acid but not tyrosol, can scavenge free radical NO (NФand peroxynitrite in a concentration dependant fashion. Altogether, these features of oleuropein and hydroxytyrsol might contribute to increase of NO levels and to prevent formation of the powerful oxidant peroxinitrite [182].

Besides the antioxidant properties of the phenolic compounds from extra VOO, antiinflammatory effects have been demonstrated in several cell types. De la Puerta et al. [183] studied a range of $\mathrm{VOO}$ phenolics in rat peritoneal leukocytes, finding inhibition of 4TB production by oleuropein glycosyde, caffeic acid and tyrosol. This had already been described in human platelets and leukocytes $[184,185]$. Hydroxytyrosol has also demonstrated inhibitory effects on LOX [185] in leukocytes, presumably by penetrating in cell membranes [186]. The inhibition of LTB production from arachidonic acid may lead to reduced platelet aggregation $[184,187]$. 
It has been described that some phenolic compounds may inhibit cytokine and eicosanoid production by inhibiting the IL-1 $\beta$ mRNA and protein expression, and the activity and transcription of COX-2 $[183,185,188]$, which may contribute to the antiatherogenic properties ascribed to extra VOO. Miles et al., [188] showed a very strong effect of oleuropein glycoside but none of the phenolic compounds from olive oil studied was able to affect the production of IL- 6 or TNF- $\alpha$. However, these authors did not use oleuropein aglycone or hydroxytyrosol in their experiments.

Monocyte adhesion to endothelial cells can also been modulated by VOO phenolic compounds. Carluccio et al. [189] incubated oleuropein, hydroxytyrosol and tyrosol with LPS or cytokine-stimulated HUVECs and observed inhibition of the expression of VCAM-1, ICAM-1 and E-selectin and the adhesion of monocytes. The oleuropein aglycone and hydroxytyrosol were the most potent phenolic compounds, which is consistent with their higher antioxidant activity. In contrast, to the study of Miles et al., [188] the oleuropein glycoside showed a low activity on adhesion molecule expression, which was attributed to its lower lipophilicity, and the consequent lower incorporation into membranes and interaction with lipids. mRNA expression for VCAM-1 was also affected, indicating a pretranscriptional action of the phenolic compounds. These authors observed a repression of the transcription factors NFKB and AP-1, the interaction of which are known to amplify VCAM-1 promoter activation [190]. Very recently, Turner et al. [191] also reported increased VCAM-1 and ICAM-1 production by VOO phenolics (namely oleuropein, hydroxytyrosol, tyrosol and homovanillic alcohol) but no influence on NO production or platelet aggregation. Activation of NF- $\mathrm{KB}$ involves complex signal transduction pathways that ultimately result in the activation of a specifiokB kinase (IKK) and translocation of NKB from cytoplasm to the nucleus. In an attempt of elucidating the mechanisms by which phenolic compounds inhibit $\mathrm{NF} \kappa \mathrm{B}, \mathrm{Ma}$ et al. [192] showed that these compounds do not inhibit activation of IKK activity, degradation of $k \mathrm{~B} \alpha$, a component of the cytoplasmic NAB complex, or translocation of activated NFKB to the nucleus, but they block the formation of NF $\kappa B / D N A$ binding complexes. These authors suggested that this blockade involves the antioxidant property of the phenolic compounds. 


\subsubsection{Effects of the unsaponifiable fraction}

The unsaponifiable fraction of VOO is also rich in other minor components with antioxidant and anti-inflammatory properties, such as tocopherols, sterols or terpenic compounds [193195].

The investigation of the effects of the unsaponifiable fraction of olive oil as a whole is almost an unexplored field. Ochoa et al., [196] investigated the influence of VOO and HOSO, with different unsaponifiable fractions on the fatty acid composition and lipid peroxidation of LDL in rabbits. The main outcome of the study was the lower susceptibility of LDL oxidation and higher antioxidant content in LDL of animals fed the diet enriched in VOO, which was attributed to the higher phenolic content in this oil. Unfortunately, as stated above, the phenolic compounds of olive oil are not included in the unsaponifiable fraction.

We recently incubated endothelial cells with postprandial TRL derived from the intake by healthy subjects of meals containing VOO, HOSO and VOO enriched in its unsaponifiable fraction (EVO) to a final concentration of $2.4 \%$ [124]. The unsaponifiable fraction of VOO was richer in squalene, terpenic compounds and waxes (long-chain fatty alcohols), whereas HOSO presented a higher concentration in tocopherols. The total concentration in sterols was similar between VOO and HOSO but in EVO, was almost double. We found a reduction in the production of PGEand TXB ${ }_{2}$ after the incubation with EVO-TRL, compared with VOO and HOSO (Figure 2), but no effect on NO production. These results suggest that minor components from VOO that are transported postprandially in TRL may have favourable effects on endothelial function by improving the balance between vasoprotective and prothrombotic factors released by endothelial cells. Despite the beneficial effects attributed to phenolic compounds it is very unlikely that they were responsible for the effects observed in this study: firstly, because its concentration in VOO and EVO was very similar, secondly, because due to their hydrophilic nature they are readily transported into plasma and not to TRL and thirdly because they appear not to affect COX activity [183]. Therefore we suggested that tocopherols, sterols or terpenoids might be responsible for the effects observed.

Vitamin E, comprising tocopherols, tocotrienols and some of their derivatives, has a protective role against the attacks of free radicals, by acting as lipid based radical chain breaking molecules [197]. More recently, non-antioxidant functions of vitamin E have been 
proposed, in particular as gene regulator, which seems to be unrelated to its radical chain breaking potential [198].

Apart from protecting LDL from lipid peroxidation [199-20zbcopherol has an inhibitory effect on LDL- and cytokine-induced production and expression of adhesion molecules [203205] and adhesion of monocytes to endothelial cells, probably by inhibition of ICAM-1 expression $[204,206]$. In cells stimulated with $\mid \mathbf{\beta}$; $\mathbf{b}$-tocopherol reduces the upregulation of ICAM-1, VCAM-1 [207] and E-selectin [206], but more importantly, it can also regulate the production of IL-1 $\beta$ by down-regulating its gene expression [208]. However, the effect on adhesion molecules seems not be mediatedklaynkfbilisation $[159,206]$.

Vitamin E can also modulate eicosanoid metabolism in endothelial cells. Actually, BGI synthesis in impaired in vitamin E-deficient mice [209-210] and it can restore redu६ed PGI synthesis in endothelial cells $[211,212]$. In addition, there are data indicating thatotocopherol inhibits 5-LOX [213] and COX-2 [214]. In a series of studies carried out by Meidani et al. [215-217] these authors demonstrated thatocopherol can eliminate the increase in PGE $2, T X A_{2}$ and TXB 2 by reducing the activity of COX in LPS-stimulated macrophages from aged-mice. This effect was found not to be due to regulation of COX transcription or translation, but to the effectetcopherol scavenging hydroperoxydes and NO, which leads to lower production of peroxynitrites. There is data suggesting that peroxinitrites may modulate COX activation via $\mathrm{Ca}^{2}$-dependent PLA2 activity and AA release [218].

Finally, pretreatment of endothelial cells with vitamin E, prevents alterations in the plasma membrane by hydrogen peroxide [219] and decreases oxidized LDL-mediated degradation of $\mathrm{I}-\mathrm{KB}$ and apoptosis [220].

However not all tocopherols have same effectsx-tocopherol, but not $\beta$-tocopherol can regulate AP-1 [221] and integrin [222] gene expression. Inhibition of the induction of VCAM-1 and E-selectine by IL-1 $\beta$ was time and dose-dependentof-tocopheryl succinate, but not for IL-1- $\beta$ [223]. In fact, $\alpha$-tocopheryl succinate can inhibit cytokine-induced mobilisation of NFKB [223], by activating caspase-3 and caspase-6, which cleave the p65 subunit of the transcription factor [224,225]. According to Christen et al. $\gamma[$ 202cospherol 
can inhibit peroxynitrite-induced peroxidation more effectivelyxttheropherol. Hencextocopherol isomers might inhibit COX activity more effectively than-tocopherol itself [214]. Nevertheless, there is controversy regarding the in vivo and long-term effects of vitamin $\mathrm{E}$ and it is not clear what amounts or combinations may be beneficial in preventing chronic diseases [197].

There are studies in humans and animals evidencing that plant sterol supplementation, including the most abundant in VOSsitosterol, can cause a decrease in serum cholesterol concentration [227, 228]. One of the principal mechanisms by which this effect has been explained is through inhibition of the absorption of cholesterol [229]. Despite of this, a recent study carried out by $\mathrm{Ho}$ et al. [230] suggests that the mechanisms also involve decreased production of the apoB-containing lipoproteins from the liver and intestine. However, very little is known about their effect on vascular function. De Jongh et al, [231] administrated a mixture of phytostero|ß-\$itosterol, campesterol, stigmasterol and others) to 41 children with familial hypercholesterolemia, finding a reduction in LDL-cholesterol but no effect on endothelial dysfunction as measured by FMD. However, de la Puerta et al. [194] had reported that $\beta$-sitosterol has antiinflamatory effects as it can reduce the auricular edema induced by TPA in mice. The effect was as high as that of hydroxytyrosol or oleuropein. Moreno [232] incubated phorbol ester (PMA)-stimulated RAW 264.7 macrophage \$tsitbsterol, which was responsible for a reduction in ROS production and arachidonic acid release. ROS modulation may regulate the release of arachidonic acid by phospholipase $A 2$, as well as the induction of COX-2 through NKB activation. By this mechanisßasitosterol might reduce $\mathrm{PGE}_{2}$ and LTB ${ }_{4}$ production by macrophages, as observed in this study. Subsequently, this author reported that $\beta$-sitosterol can regulate the GSH redox cycle, enhancing GSH peroxidase and superoxide dismutase activities, hence decreasing superoxide anion levels although no ROS scavenger activity was found.

The potential therapeutic importance of olive oil triterpenoids, encompassed of acids and alcohols, has not been extensively studied. Although their presence in VOO is very low, in olive pomace oil is very significant, as it can be as high as $120 \mathrm{mg} / \mathrm{kg}$. For that reason, the concentration of triterpenic alcohols is used as a parameter of purity for the presence of pomace oil in VOO [233]. 
Oleanolic acid has been identified in multitude of medicinal plants [234] and has been reported to possess a number of biological pharmacological activities, including some affecting inflammation [235]. Oleanolic acid inhibits LOX and COX-2 activities [236,237], therefore reducing the production of PEefend LTB ${ }_{4}$. Additionally, it has been shown that oleanolic acid can inhibit the generation of the superoxide anion by human neutrophils, which might occur through the protein-kinase independent pathway [238]. Although it has been attributed anti-inflammatory activities to the triterpenic alcohol erythrodiol, its mechanism of action is still unknown. Erythrodiol is able to reduce the edema caused by TPA, with a possible action on PLA2 [194].

We recently developed a study to evaluate the properties as vasodilator agents of oleanolic acid and erythrodiol and to determine their mechanism of action [195]. The vasorelaxant effect induced by these triterpenoids was studied in isolated thoracic rat aorta. Results from this work introduced the first in vitro evidence that oleanolic acid and erythrodiol evoke an endothelium-dependent vasorelaxation in rat aorta, and suggested that the mechanism of relaxation is mainly mediated by the endothelial production of NO (Figure 3). According with the pharmacological effects obtained, it was concluded that oleanolic acid and erythrodiol may have interesting therapeutic potential as new vasodilator drugs, being able to protect the cardiovascular system.

\section{Conclusion}

It is becoming clear that the content of oleic acid alone can not fully explain the impact on health of olive oil and that being $\mathrm{VOO}$ an unique fruit-derived oil it is rich in a number of minor compounds with relevant physiological and pharmacological functions. Among these compounds, tocopherols and phenolic compounds have demonstrated antioxidant properties, which may improve the endothelial function by reducing levels of ROS in the endothelium and, consequently, the production of eicosanoids and adhesion molecules. However, there are other less studied compounds that have been proved to exert important effects on the endothelial function. Phytosterols and triterpenoids have anti-inflammatory and vasorelaxant effects, respectively but their roles in the endothelium need to be further studied. The increasing investigations on the properties of these minor compounds are not only helping to explain some of the classical beneficial effects of the Mediterranean diet and VOO itself but 
also to the emergence of other olive-derived oils, such as pomace olive oil, which being more enriched in these minor components, might be helpful for the prevention of CVD. 


\section{References}

1. Murray CJ, Lopez AD. Alternative projections of mortality and disability by cause 1990-2020: Global Burden of Disease Study. Lancet 1997; 349:1498-504.

2. Fuster V. Epidemic of cardiovascular disease and stroke: the three main challenges. Presented at the 71st scientific sessions of the American Heart Association. Dallas, Texas. Circulation 1999;99(9):1132-7.

3. Hennig B, Toborek M, McClain CJ. High-energy diets, fatty acids and endothelial cell function: implications for atherosclerosis. J Am Coll Nutr 2001;20(2 Suppl):97-105.

4. Cooke JP. The endothelium: a new target for therapy. Vasc Med 2000;5:49-53.

5. Vane JR, Born GVR, Welzel D, eds. The endothelial cell in health and disease. Stuttgart, Germany: Schattauer, 1995.

6. Duvall WL. Endothelial dysfunction and antioxidants. Mt Sinai J Med 2005;72(2):71-80.

7. Ross R. Atherosclerosis-an inflammatory disease. N Engl J Med 1999;340:115-49.

8. Davies MJ, Gordon JL, Gearing AJ, Pigott R, Woolf N, Katz D, Kyriakopoulos A. The expression of adhesion molecules ICAM-1, VCAM-1, PECAM, and E-selectin in human atherosclerosis. J Pathol 1993;171:223-9.

9. Hennig $B$, Toborek M. Nutrition and endothelial cell function: implications in atherosclerosis. Nutr Res 2001;21(1-2):279-93.

10. Vogel RA. Coronary risk factors, endothelial function and atherosclerosis: a review. Clin Cardiol 1997;20:426-32.

11. Ross R.. Cell biology of atherosclerosis. Annu Rev Physiol 1995; 57:791-804.

12. Shimokawa H. Primary endothelial dysfunction: atherosclerosis. J Mol Cell Cardiol 1999;31:23-7.

13. Moncada S, Higgs A. The L-arginine-nitric oxide pathway. N Engl J Med 1993; 329(27):2002-12.

14. Tsao PS, Buitrago R, Chan JR, Cooke JP. Fluid flow inhibits endothelial adhesiveness: nitric oxide and transcriptional regulation of VCAM-1. Circulation 1996;94:1682-9.

15. Kinlay S, Ganz P. Relation between endothelial dysfunction and the acute coronary syndrome: implications for therapy. Am J Cardiol 2000; 86:10J-14J.

16. Gimbrone MA Jr., Topper JN, Nagel T, Anderson KR, Garcia-Cardena G. Endothelial dysfunction, hemodynamic forces, and atherogenesis. Ann N Y Acad Sci 2000;902:2309.

17. Vogel RA. Measurement of endothelial function by brachial artery flow-mediated vasodilation. Am J Cardiol 2001;88(2A):31E-34E.

18. Kelm M. Flow-mediated dilatation in human circulation: diagnostic and therapeutic aspects. Am J Physiol Heart Circ Physiol 2002;282(1):H1-5.

19. Faulx MD, Wright AT, Hoit BD. Detection of endothelial dysfunction with brachial artery ultrasound scanning. Am Heart J 2003;145(6):943-51.

20. Dimmeler S, Fleming I, Fisslthaler B, Hermann C, Busse R, Zeiher A. Activation of nitric oxide synthase in endothelial cells by Akt-dependent phosphorylation. Nature 1999;399(6736):601-5. 
21. Moens AL, Goovaerts I, Claeys MJ, Vrints CJ. Flow-mediated vasodilation: a diagnostic instrument, or an experimental tool? Chest 2005;127(6):2254-63.

22. Schnell GB, Robertson A, Houston D, Malley L, Anderson TJ. Impaired brachial artery endothelial function is not predicted by elevated triglycerides. J Am Coll Cardiol 1999;33(7):2038-43.

23. Vogel RA, Corretti MC, Gellman J. Cholesterol, cholesterol lowering, and endothelial function. Prog Cardiovasc Dis 1998;41(2):117-36.

24. Vogel RA, Corretti MC, Plotnick GD. Effect of a single high-fat meal on endothelial function in healthy subjects. Am J Cardiol 1997;79(3):350-4.

25. Vogel RA, Corretti MC, Plotnick GD. The postprandial effect of components of the Mediterranean diet on endothelial function. J Am Coll Cardiol 2000;36(5):1455-60.

26. Voetsch B, Jin RC, Loscalzo J. Nitric oxide insufficiency and atherothrombosis. Histochem Cell Biol 2004;122(4):353-67.

27. Triggle CR, Hollenberg $M$, Anderson TJ, Ding H, Jiang $Y$, Ceroni L, Wiehler WB, Ng ES, Ellis A, Andrews K, McGuire JJ, Pannirselvam M. The endothelium in health and disease--a target for therapeutic intervention. J Smooth Muscle Res 2003;39(6):249-67.

28. Ohara Y, Peterson TE, Harrison DG. Hypercholesterolemia increases endothelial superoxide anion production. J Clin Invest 1993;91:2546-51.

29. Stokes KY, Cooper D, Tailor A, Granger DN. Hypercholesterolemia promotes inflammation and microvascular dysfunction: role of nitric oxide and superoxide. Free Radic Biol Med 2002;33:1026-36.

30. Guzik TJ, Mussa S, Gastaldi D, Sadowski J, Ratnatunga C, Pillai R, Channon KM. Mechanisms of increased vascular superoxide production in human diabetes mellitus: role of $\mathrm{NAD}(\mathrm{P}) \mathrm{H}$ oxidase and endothelial nitric oxide synthase. Circulation 2002;105:1656-62.

31. Just A. Nitric oxide and renal autoregulation. Kidney Blood Press Res 1997; 20:201-4.

32. Kerr S, Brosnan MJ, McIntyre M, Reid JL, Dominiczak AF, Hamilton CA. Superoxide anion production is increased in a model of genetic hypertension: role of the endothelium. Hypertension 1999;33:1353-58.

33. Chin JH, Azhar S, Hoffman BB. Inactivation of endothelial derived relaxing factor by oxidized lipoproteins. J Clin Invest 1992;89:10-8.

34. Quinn MT, Parthasarathy S, Fong LG, Steinberg D. Oxidatively modified low density lipoproteins: a potential role in recruitment and retention of monocyte/macrophages during atherogenesis. Proc Natl Acad Sci USA 1987; 84(9):2995-8.

35. Kuhn FE, Mohler ER, Salter LF, Reagan K, Lu DY, Rackley CE. Effects of highdensity lipoprotein on acetylcholine-induced coronary vasoreactivity. Am J Cardiol 1991;68:1425-30.

36. Verges BL. Dyslipidemia in diabetes mellitus. Diabet Metab 1999;25:32-40.

37. Gotto AM. Triglyceride as a risk factor for coronary artery disease. Am J Cardiol 1998;5:22Q-5Q.

38. Rapp RJ. Hypertriglyceridemia: a review beyond low-density lipoprotein. Cardiol Rev 2002;10(3):163-72. 
39. Durrington PN. Triglycerides are more important in atherosclerosis than epidemiology has suggested. Atherosclerosis 1998;141 Suppl 1:S57-S62.

40. Roche HM, Gibney MJ. Effect of long-chain $n-3$ polyunsaturated fatty acids on fasting and postprandial triacylglycerol metabolism. Am J Clin Nutr 2000;71:232S-7S.

41. Abe Y, El-Masri B, Kimball KT, Pownall H, Reilly CF, Osmundsen K, Smith CW and Ballantyne CM. Soluble cell adhesion molecules in hypertriglyceridemia and potential significance on monocyte adhesion. Arterioscler Thromb Vasc Biol 1998;18:723-31.

42. Patsch JR, Miesenbock G, Hopferwieser T, Muhlberger V, Knapp E, Dunn JK, Gotto AM Jr, Patsch W. Relation of triglyceride metabolism and cardiovascular disease. Arterioscl Thromb Vasc Biol 1992;12:1336-45.

43. Mamo JC, Wheeler JR. Chylomicrons or their remnants penetrate rabbit thoracic aorta as efficiently as do smaller macromolecules, including low-density lipoprotein, highdensity lipoprotein, and albumin. Coron Artery Dis 1994;5:695-705.

44. Napolitano M, Avella M, Botham KM, Bravo E. Chylomicron remnant induction of lipid accumulation in $\mathbf{7 7 4}$ macrophages is associated with up-regulation of triacylglycerol synthesis which is not dependent on oxidation of the particles. Biochim Biophys Acta 2003;1631(3):255-64.

45. Stender S, Zilversmit DB. Transfer of plasma lipoprotein components and of plasma proteins into aortas of cholesterol-fed rabbits. Molecular size as a determinant of plasma lipoprotein influx. Arteriosclerosis 1981;1(1):38-49.

46. Nordestgaard BG, Zilversmit DB. Large lipoproteins are excluded from the arterial wall in diabetic cholesterol-fed rabbits. J Lipid Res 1988;29(11):1491-500.

47. Cohn JS, Marcoux C, Davignon J. Detection, quantification, and characterization of potentially atherogenic triglyceride-rich remnant lipoproteins. Arterioscler Thromb Vasc Biol. 1999;19(10):2474-86.

48. Hennig B, Shasby DM, Fulton AB, Spector AA. Exposure to free fatty acid increases the transfer of albumin across cultured endothelial monolayers. Arteriosclerosis 1984;4(5):489-97.

49. Hennig B, Chung BH, Watkins BA, Alvarado A. Disruption of endothelial barrier function by lipolytic remnants of triglyceride-rich lipoproteins. Atherosclerosis 1992;95(2-3):235-47.

50. Doi H, Kugiyama K, Ohgushi M, Sugiyama S, Matsumura T, Ohta Y, Nakano T, Nakajima K, Yasue H. Remnants of chylomicron and very low density lipoprotein impair endothelium-dependent vasorelaxation. Atherosclerosis 1998;137(2):341-9.

51. Kugiyama K, Doi H, Motoyama T, Soejima H, Misumi K, Kawano H, Nakagawa O, Yoshimura M, Ogawa H, Matsumura T, Sugiyama S, Nakano T, Nakajima K, Yasue H. Association of remnant lipoprotein levels with impairment of endothelium-dependent vasomotor function in human coronary arteries. Circulation 1998;97(25):2519-26.

52. Eriksson P, Nilsson L, Karpe F, and Hamstem A. Very-low-density lipoprotein response element in the promoter region of the human plasminogen activator inhibitor-1 gene implicated in the impaired fibrinolysis of hypertriglyceridemia. Arterioscler Thromb Vasc Biol 1998;18:20-6.

53. Wilhelm MG, Cooper AD. Induction of atherosclerosis by human chylomicron remnants: a hypothesis. J Atheroscler Thromb 2003;10(3):132-9. 
54. Saigo M, Abe S, Ogawa M, Biro S, Minagoe S, Maruyama I, Toda H, Kiyonaga K, Atsuchi $Y$, Tahara M, Mawatari K, and Tei C. Plasma level of triglyceride-rich lipoprotein remnants is closely associated with the activation of coagulation factor VII in patients with myocardial infarction. Thromb Res 2000;100:9-17.

55. Dart AM, Chin-Dusting JP. Lipids and the endothelium. Cardiovasc Res 1999;43: 30822.

56. Doi H, Kugiyama K, Oka H, Sugiyama S, Ogata N, Koide SI, Nakamura SI, Yasue H. Remnant lipoproteins induce proatherothrombogenic molecules in endothelial cells through a redox-sensitive mechanism. Circulation 2000;102: 670-76.

57. Moers A, Fenselau S, Schrezenmeir J. Chylomicrons induce E-selectin and VCAM-1 expression in endothelial cells. Exp Clin Endocrinol Diabetes 1997;105 Suppl 2:35-7.

58. Kusterer K, Pohl T, Fortmeyer HP, Marz W, Scharnagl H, Oldenburg A, Angermuller S, Fleming I, Usadel KH, Busse R. Chronic selective hypertriglyceridemia impairs endothelium-dependent vasodilatation in rats. Cardiovasc Res J 1999;42:783-93.

59. Van Eck M, Zimmermann R, Groot PH, Zechner R, Van Berkel TJ. Role of macrophage-derived lipoprotein lipase in lipoprotein metabolism and atherosclerosis. Arterioscler Thromb Vasc Biol 2000;20:E53-E62.

60. Khoo JC, Mahoney EM, Witztum JL. Secretion of lipoprotein lipase by macrophages in culture. J Biol Chem 1981;256:7105-8.

61. Ylä-Herttuala S, Lipton BA, Rosenfeld ME, Goldberg IJ, Steinberg D, Witztum JL: Macrophages and smooth muscle cells express lipoprotein lipase in human and rabbit atherosclerotic lesions. Proc Natl Acad Sci USA 1991;88:10143-7.

62. O'Brien KD, Gordon D, Deeb S, Ferguson M, Chait A. Lipoprotein lipase is synthesized by macrophage-derived foam cells in human coronary atherosclerotic plaques. J Clin Invest 1992;89:1544-50.

63. Sofer O, Fainaru M, Schafer Z, Goldman R. Regulation of lipoprotein lipase secretion in murine macrophages during foam cell formation in vitro. Effect of triglyceride-rich lipoproteins. Arterioscler Thromb 1992;12:1458-66.

64. Saxena U, Klein MG, Vanni TM, Goldberg IJ. Lipoprotein lipase increases low density lipoprotein retention by subendothelial cell matrix. J Clin Invest 1992;89: 373-80.

65. Edwards IJ, Goldberg IJ, Parks JS, Xu H, Wagner WD. Lipoprotein lipase enhances the interaction of low density lipoproteins with artery-derived extracellular matrix proteoglycans. J Lipid Res 1993;34:1155-63.

66. Mamputu JC, Desfaits AC, Renier G. Lipoprotein lipase enhances human monocyte adhesion to aortic endothelial cells. J Lipid Res 1997;38:1722-29.

67. Hirata K, Ishida T, Matsushita H, Tsao PS, Quertermous T. Regulated expression of endothelial cell-derived lipase. Biochem Biophys Res Commun 2000;272:90-3.

68. McCoy MG, Sun GS, Marchadier D, Maugeais C, Glick JM, Rader DJ. Characterization of the lipolytic activity of endothelial lipase. J Lipid Res 2002;43(6):921-9.

69. Jin W, Sun GS, Marchadier D, Octtaviani E, Glick JM, Rader DJ. Endothelial cells secrete triglyceride lipase and phospholipase activities in response to cytokines as a result of endothelial lipase. Circ Res 2003;92(6):644-50. 
70. Traenckner EB, Pahl HL, Henkel T, Schmidt KN, Wilk S, Baeuerle PA: Phosphorylation of human I kappa B-alpha on serines 32 and 36 controls I kappa Balpha proteolysis and NF-kappa B activation in response to diverse stimuli. EMBO J 1995; 14:2876-83.

71. Steinberg HO, Tarshoby M, Monestel R, Hook G, Cronin J, Johnson A, Bayazeed B, Baron AD. Elevated circulating free fatty acid levels impair endothelium-dependent vasodilation. J Clin Invest 1997;100(5):1230-9.

72. Inoguchi T, Li P, Umeda F, Yu HY, Kakimoto M, Imamura M, Aoki T, Etoh T, Hashimoto T, Naruse M, Sano H, Utsumi H, Nawata H. High glucose level and free fatty acid stimulate reactive oxygen species production through protein kinase C-dependent activation of $\mathrm{NAD}(\mathrm{P}) \mathrm{H}$ oxidase in cultured vascular cells. Diabetes 2000;49(11):1939-45.

73. Williams CM, Maitin V, Jackson KG. Triacylglycerol-rich lipoprotein-gene interactions in endothelial cells. Biochem Soc Trans 2004;32:994-8.

74. Toborek M, Barger SW, Mattson MP, Barve S, McClain CJ, Hennig B. Linoleic acid and TNF-alpha cross-amplify oxidative injury and dysfunction of endothelial cells. J Lipid Res 1996;37(1):123-35.

75. Young VM, Toborek M, Yang F, McClain CJ, Hennig B. Effect of linoleic acid on endothelial cell inflammatory mediators. Metabolism 1998;47:566-5.

76. Rus HG, Vlaicu R, Niculescu F. Interleukin- 6 and interleukin-8 protein and gene expression in human arterial atherosclerotic wall. Atherosclerosis 1996;127:263-71.

77. Yudkin JS, Kumari M, Humphries SE, Mohamed-Ali V. Inflammation, obesity, stress and coronary heart disease: is interleukin-6 the link? Atherosclerosis 2000;148: 209-14.

78. De Caterina R, Cybulsky MI, Clinton SK, Gimbrone MA, Libby P. The omega-3 fatty acid docosahexaenoate reduces cytokine-induced expression of proatherogenic and proinflammatory proteins in human endothelial cells. Arterioscler Thromb 1994;14:1829-36.

79. Weber C, Erl W, Pietsch A, Danesch U, Weber P. Docosahexaenoic acid selectively attenuates induction of vascular cell adhesion molecule-1 and subsequent monocytic adhesion to human endothelial cells stimulated by tumor necrosis factor-alpha. Arterioscler Thromb Vasc Biol 1995;15:622-8.

80. Khalfoun B, Thibault G, Bardos P, Lebranchu Y. Docosahexaenoic and eicosapentaenoic acids inhibit in vitro human lymphocyte-endothelial adhesion. Transplantation 1996;62:1649-57.

81. Seljeflot I, Arnesen H, Brude IR, Nenseter MS, Drevon CA, Hjermann I. Effects of omega-3 fatty acids and/or antioxidants on endothelial cell markers. Eur J Clin Invest 1998;28:629-35.

82. Johansen O, Seljflot I, Hostmark AT, Arnesen H. The effect of supplementation with omega-3 fatty acids on soluble markers of endothelial function in patients with coronary heart disease. Arterioscler Thromb Vasc Biol 1999;19:1681-6.

83. Hawkes JS, James MJ, Cleland LG. Biological activity of prostaglandin E3 with regard to oedema formation in mice. Agents Actions 1992;35:85-7. 
84. Goldman DW, Pickett WC, Goetzl EJ. Human neutrophil chemotactic and degranulating activities of leukotriene B5 (LTB5) derived from eicosapentaenoic acid. Biochem Biophys Res Commun 1983;117:282-8.

85. James MJ, Cleland LG, Gibson RA, Hawkes JS. Interaction between fish and vegetable oils in relation to rat leucocyte leukotriene production. J Nutr 1991;121:631-7.

86. Wahrburg U, Kratz M, Cullen P. Mediterranean diet, olive oil and health. Eur J Lipid Sci Technol 2002;104:698-705.

87. Keys A, Menotti A, Karvonen MJ, Aravanis C, Blackburn H, Buzina R, Djordjevic BS, Dontas AS, Fidanza F, Keys MH, et al. The diet and 15-year death rate in the seven countries study. Am J Epidemiol 1986;124(6):903-15.

88. de Lorgeril M, Renaud S, Mamelle N, Salen P, Martin JL, Monjaud I, Guidollet J, Touboul P, Delaye J. Mediterranean alpha-linolenic acid-rich diet in secondary prevention of coronary heart disease. Lancet 1994;343:1454-9.

89. Trichopoulou A, Costacou T, Bamia C, Trichopoulos D. Adherence to a Mediterranean diet and survival in a Greek population. N Engl J Med 2003;348(26):2599-608.

90. Trichopoulou A, Bamia C, Trichopoulos D. Mediterranean diet and survival among patients with coronary heart disease in Greece. Arch Intern Med 2005;165(8):929-35.

91. Hu FB. The Mediterranean diet and mortality-olive oil and beyond. N Engl J Med 2003;348(26):2595-6.

92. Mensink RP, Katan MB. Effect of dietary fatty acids on serum lipids and lipoproteins. A meta-analysis of 27 trials. Arterioscler Thromb 1992;12(8):911-9.

93. Gardner CD, Kraemer HC. Monounsaturated versus polyunsaturated dietary fat and serum lipids. A meta-analysis.Arterioscler Thromb Vasc Biol 1995;15(11):1917-27.

94. Kris-Etherton PM, Pearson TA, Wan Y, Hargrove RL, Moriarty K, Fishell V, Etherton TD. High-monounsaturated fatty acid diets lower both plasma cholesterol and triacylglycerol concentrations. Am J Clin Nutr 1999;70(6):1009-15.

95. Mata P, Garrido JA, Ordovas JM, Blazquez E, Alvarez-Sala LA, Rubio MJ, Alonso R, de Oya M. Effect of dietary monounsaturated fatty acids on plasma lipoproteins and apolipoproteins in women. Am J Clin Nutr 1992;56(1):77-83.

96. Perona JS, Canizares J, Montero E, Sanchez-Dominguez JM, Ruiz-Gutierrez V. Plasma lipid modifications in elderly people after administration of two virgin olive oils of the same variety (Olea europaea var. hojiblanca) with different triacylglycerol composition. Br J Nutr 2003;89(6):819-26.

97. Perona JS, Canizares J, Montero E, Sanchez-Dominguez JM, Catala A, Ruiz-Gutierrez V. Virgin olive oil reduces blood pressure in hypertensive elderly subjects. Clin Nutr 2004;23(5):1113-21.

98. Aguilera CM, Mesa MD, Ramirez-Tortosa MC, Nestares MT, Ros E, Gil A. Sunflower oil does not protect against LDL oxidation as virgin olive oil does in patients with peripheral vascular disease. Clin Nutr 2004;23(4):673-81.

99. Aranda P. Arterial hypertension in Spain: the experience of the Spanish League. J Hum Hypertens 1996;10 Suppl 1:S73-S5. 
100. Coulston AM, Hollenbeck CB, Swislocki AL, Reaven GM. Persistence of hypertriglyceridemic effect of low-fat high-carbohydrate diets in NIDDM patients. Diabetes Care 1989;12(2):94-101.

101. Appel LJ, Miller ER 3rd, Seidler AJ, Whelton PK. Does supplementation of diet with 'fish oil' reduce blood pressure? A meta-analysis of controlled clinical trials. Arch Intern Med 1993;153(12):1429-38.

102. Lam BK, Marcinkiewicz E, Quilley J, Hirai A, Yoshida S, Tamura Y, Wong PY. Hypotensive effects of eicosapentaenoic acid (EPA) and its influence on eicosanoid metabolism in spontaneously hypertensive rats. J Hypertens Suppl 1986;4(3):S453-S5.

103. Perez-Jimenez F, Lopez-Miranda J, Mata P. Protective effect of dietary monounsaturated fat on arteriosclerosis: beyond cholesterol. Atherosclerosis 2002;163(2):385-98.

104. Espino A, López-Miranda J, Castro P, Rodríguez M, López F, Blanco A, et al. Monounsaturated fatty acids enriched diets lower plasma insulin levels and blood pressure in healthy young men. Nutr Met Card Dis 1996;6:147-54.

105. Lahoz C, Alonso R, Ordovas JM, Lopez-Farre A, de Oya M, Mata P. Effects of dietary fat saturation on eicosanoid production, platelet aggregation and blood pressure. Eur J Clin Invest 1997;27(9):780-7.

106. Ruiz-Gutierrez V, Muriana FJ, Guerrero A, Cert AM, Villar J. Plasma lipids, erythrocyte membrane lipids and blood pressure of hypertensive women after ingestion of dietary oleic acid from two different sources. J Hypertens 1996;14(12):1483-90.

107. Psaltopoulou T, Naska A, Orfanos P, Trichopoulos D, Mountokalakis T, Trichopoulou A. Olive oil, the Mediterranean diet, and arterial blood pressure: the Greek European Prospective Investigation into Cancer and Nutrition (EPIC) study. Am J Clin Nutr 2004;80(4):1012-8.

108. Mills DE, Ward RP, Mah M, DeVette L. Dietary N-6 and N-3 fatty acids and saltinduced hypertension in the borderline hypertensive rat. Lipids 1989;24(1):17-24.

109. Berry EM, Eisenberg S, Haratz D, Friedlander Y, Norman Y, Kaufmann NA, Stein Y. Effects of diets rich in monounsaturated fatty acids on plasma lipoproteins--the Jerusalem Nutrition Study: high MUFAs vs high PUFAs. Am J Clin Nutr 1991;53(4):899-907.

110. Reaven P, Parthasarathy S, Grasse BJ, Miller E, Almazan F, Mattson FH, Khoo, JC, Steinberg D, Witztum JL. Feasibility of using an oleate-rich diet to reduce the susceptibility of low-density lipoprotein to oxidative modification in humans. Am J Clin Nutr 1991;54(4):701-6.

111. Bonanome A, Pagnan A, Biffanti S, Opportuno A, Sorgato F, Dorella M, Maiorino M, Ursini F. Effect of dietary monounsaturated and polyunsaturated fatty acids on the susceptibility of plasma low density lipoproteins to oxidative modification. Arterioscler Thromb 1992;12(4):529-33.

112. Reaven P, Grasse B, Barnett J. Effect of antioxidants alone and in combination with monounsaturated fatty acid-enriched diets on lipoprotein oxidation. Arterioscler Thromb Vasc Biol 1996;16(12):1465-72.

113. Hargrove RL, Etherton TD, Pearson TA, Harrison EH, Kris-Etherton PM. Low fat and high monounsaturated fat diets decrease human low density lipoprotein oxidative susceptibility in vitro. J Nutr 2001;131(6):1758-63. 
114. Truswell AS, Choudhury N. Monounsaturated oils do not all have the same effect on plasma cholesterol.Eur J Clin Nutr 1998;52(5):312-5.

115. Muriana FJ, Villar J, Ruiz-Gutierrez V. Intake of olive oil can modulate the transbilayer movement of human erythrocyte membrane cholesterol. Cell Mol Life Sci 1997;53(6):496-500.

116. Perona JS, Ruiz-Gutierrez V. Effect of two high-oleic oils on the liver lipid composition of spontaneously hypertensive rats. Life Sci 2000;66(6):521-31.

117. Perona JS, Ruiz-Gutierrez V. Virgin olive oil normalizes the altered triacylglycerol molecular species composition of adipose tissue in spontaneously hypertensive rats. J Agric Food Chem 2004;52(13):4227-33.

118. Perona JS, Ruiz-Gutierrez V. Triacylglycerol molecular species are depleted to different extents in the myocardium of spontaneously hypertensive rats fed two oleic acid-rich oils. Am J Hypertens 2005;18(1):72-80.

119. Herrera MD, Perez-Guerrero C, Marhuenda E, Ruiz-Gutierrez V. Effects of dietary oleic-rich oils (virgin olive and high-oleic-acid sunflower) on vascular reactivity in Wistar-Kyoto and spontaneously hypertensive rats. Br J Nutr 2001;86(3):349-57.

120. Ruiz-Gutierrez V, Perona JS, Pacheco YM, Muriana FJ, Villar J. Incorporation of dietary triacylglycerols from olive oil and high-oleic sunflower oil into VLDL triacylglycerols of hypertensive patients. Eur J Clin Nutr 1999;53(9):687-93.

121. Ruiz-Gutierrez V, Morgado N, Prada JL, Perez-Jimenez F, Muriana FJ. Composition of human VLDL triacylglycerols after ingestion of olive oil and high oleic sunflower oil. J Nutr 1998;128(3):570-6.

122. Abia R, Pacheco YM, Perona JS, Montero E, Muriana FJ, Ruiz-Gutierrez V. The metabolic availability of dietary triacylglycerols from two high oleic oils during the postprandial period does not depend on the amount of oleic acid ingested by healthy men. J Nutr 2001;131(1):59-65.

123. Pacheco YM, Abia R, Perona JS, Reina M, Ruiz-Gutierrez V, Montero E, Muriana FJ. Triacylglycerol-rich lipoproteins interact with human vascular cells in a lipid-dependent fashion. J Agric Food Chem 2001;49(11):5653-61.

124. Perona JS, Martinez-Gonzalez J, Sanchez-Dominguez JM, Badimon L, Ruiz-Gutierrez $V$. The unsaponifiable fraction of virgin olive oil in chylomicrons from men improves the balance between vasoprotective and prothrombotic factors released by endothelial cells. J Nutr 2004;134(12):3284-9.

125. Scaccini C, Nardini M, D'Aquino M, Gentili V, Di Felice M, Tomassi G. Effect of dietary oils on lipid peroxidation and on antioxidant parameters of rat plasma and lipoprotein fractions. J Lipid Res 1992;33(5):627-33.

126. Nicolaiew N, Lemort N, Adorni L, Berra B, Montorfano G, Rapelli S, Cortesi N, Jacotot B. Comparison between extra virgin olive oil and oleic acid rich sunflower oil: effects on postprandial lipemia and LDL susceptibility to oxidation. Ann Nutr Metab 1998;42(5):251-60.

127. Ruiz-Gutiérrez V, De la Puerta R, Javier S. Perona. Beneficial Effects of Olive Oil on Health. In: Recent Research and Development in Nutrition. India: Researchsignpost. Trivandrum; 2000. pp. 173-197. 
128. Lanzón A, Albi T, Cert A and Gracián J. The hydrocarbon fraction of virgin olive oil and changes resulting from refining. J Am Oil Chem Soc 1994;71(3):285-91.

129. Ginda A, Lanzón A and Albi T. Differences in hydrocarbons of virgin olive oils obtained from several olive varieties. J Agric Food Chem 1993;44(7)1723-6.

130. Tiscornia EFM, Evangelisti F. Chemical composition of olive oil and its variations induced by refining. Riv Ital Sostanza Grasse 1982;59:519-56.

131. Zamora R, Navarro JL, Hidalgo FJ. Identification and classification of olive oils by high-resolution C-13 nuclear-magnetic-resonance. J Am Oil Chem Soc 1994; 71(4):3614.

132. Gutfinger T. Polyphenols in olive oils. J Am Chem Soc 1981;58(11):966-8.

133. Vazquez-Roncero $A$. Les polyphénoles de l'huile d'olive et leur influence sur les caractéristiques de l'huile. Rev Fr Corps Gras 1978;25:21-6.

134. Tsimidou M, Papadopoulos G, Boskou D. Phenolic compounds and stability of virgin olive oil. Part I. Food Chem 1992;45:141-4.

135. Boskov D. Olive oil chemistry and technology. Illinois, USA: AOCS Press; 1996. pp. 115-117.

136. Visioli F, Galli C. The effect of minor constituents of olive oil on cardiovascular disease: new findings. Nutr Rev 1998;56(5 Pt 1):142-7.

137. Visioli F, Galli C, Bornet F, Mattei A, Patelli R, Galli G, Caruso D. Olive oil phenolics are dose-dependently absorbed in humans. FEBS Lett 2000;468(2-3):159-60.

138. Weinbrenner T, Fito M, de la Torre R, Saez GT, Rijken P, Tormos C, Coolen S, Albaladejo MF, Abanades S, Schroder H, Marrugat J, Covas MI. Olive oils high in phenolic compounds modulate oxidative/antioxidative status in men. J Nutr 2004;134(9):2314-21.

139. Weinbrenner T, Fito M, Farre Albaladejo M, Saez GT, Rijken P, Tormos C, Coolen S, De La Torre R, Covas MI. Bioavailability of phenolic compounds from olive oil and oxidative/antioxidant status at postprandial state in healthy humans. Drugs Exp Clin Res 2004;30(5-6):207-12.

140. Visioli F, Caruso D, Grande S, Bosisio R, Villa M, Galli G, Sirtori C, Galli C. Virgin Olive Oil Study (VOLOS): vasoprotective potential of extra virgin olive oil in mildly dyslipidemic patients. Eur J Nutr 2005;44(2):121-7.

141. Ryan M, Mclnerney D, Owens D, Collins P, Johnson A, Tomkin GH. Diabetes and the Mediterranean diet: a beneficial effect of oleic acid on insulin sensitivity, adipocyte glucose transport and endothelium-dependent vasoreactivity. QJM 2000;93(2):85-91.

142. Fuentes F, Lopez-Miranda J, Sanchez E, Sanchez F, Paez J, Paz-Rojas E, Marin C, Gomez P, Jimenez-Pereperez J, Ordovas JM, Perez-Jimenez F. Mediterranean and lowfat diets improve endothelial function in hypercholesterolemic men. Ann Intern Med 2001;134(12):1115-9.

143. Ros E, Nunez I, Perez-Heras A, Serra M, Gilabert R, Casals E, Deulofeu R. A walnut diet improves endothelial function in hypercholesterolemic subjects: a randomized crossover trial. Circulation 2004;109(13):1609-14. 
144. Sondergaard E, Moller JE, Egstrup K. Effect of dietary intervention and lipid-lowering treatment on brachial vasoreactivity in patients with ischemic heart disease and hypercholesterolemia. Am Heart J 2003;145(5):E19.

145. Esposito K, Marfella R, Ciotola M, Di Palo C, Giugliano F, Giugliano G, D'Armiento $M$, D'Andrea F, Giugliano D. Effect of a mediterranean-style diet on endothelial dysfunction and markers of vascular inflammation in the metabolic syndrome: a randomized trial. JAMA 2004;292(12):1440-6.

146. Hennig B, Meerarani P, Ramadass P, Watkins BA, Toborek M. Fatty acid-mediated activation of vascular endothelial cells. Metabolism 2000;49(8):1006-13.

147. Carluccio MA, Massaro M, Bonfrate C, Siculella L, Maffia M, Nicolardi G, Distante A, Storelli C, De CaterinaR. Oleic acid inhibits endothelial activation: direct vascular antiatherogenic mechanism of a nutritional component in the Mediterranean diet. Arterioscler Thromb Vasc Biol 1999;19(2):220-8.

148. Tsimikas S, Philis-Tsimikas A, Alexopoulos S, Sigari F, Lee C, Reaven PD. LDL isolated from Greek subjects on a typical diet or from American subjects on an oleatesupplemented diet induces less monocyte chemotaxis and adhesion when exposed to oxidative stress. Arterioscler Thromb Vasc Biol 1999;19(1):122-30.

149. Lee C, Barnett J, Reaven PD. Liposomes enriched in oleic acid are less susceptible to oxidation and have less proinflammatory activity when exposed to oxidizing conditions. J Lipid Res 1998;39(6):1239-47.

150. Christon RA. Mechanisms of action of dietary fatty acids in regulating the activation of vascular endothelial cells during atherogenesis. Nutr Rev 2003;61(8):272-9.

151. Spolarics Z. Endotoxin stimulates gene expression of ROS eliminating pathways in rat hepatic endothelial and Kupffer cells. Am J Physiol 1996;270:660-6.

152. Baeuerle P. A., Henkel T. Function and activation of NF-kB in the immune system. Annu Rev Immunol 1994;12:141-179.

153. Massaro M, Carluccio MA, Paolicchi A, Bosetti F, Solaini G, De Caterina R. Mechanisms for reduction of endothelial activation by oleate: inhibition of nuclear factor-kappaB through antioxidant effects. Prostaglandins Leukot Essent Fatty Acids 2002;67(2-3):175-81.

154. Massaro M, Carluccio MA, De Caterina R. Direct vascular antiatherogenic effects of oleic acid: a clue to the cardioprotective effects of the Mediterranean diet. Cardiologia 1999;44(6):507-13.

155. Toborek M, Lee YW, Garrido R, Kaiser S, Hennig B. Unsaturated fatty acids selectively induce an inflammatory environment in human endothelial cells. Am J Clin Nutr 2002; 75(1):119-25.

156. Massaro M, Carluccio MA, Bonfrate C, Siculella L, Lazzerini G, Bernini W, Basta G, De Caterina R. The double bond in unsaturated fatty acids is the necessary and sufficient requirement for the inhibition of expression of endothelial leukocyte adhesion molecules through interference with nuclear factor-kappaB activation. Lipids 1999;34 Suppl:S2134.

157. De Caterina R, Cybulsky MI, Clinton SK, Gimbrone MA Jr, Libby P. The -3 fatty acid docosahexaenoate reduces cytokine-induced expression of pro-atherogenic and proinflammatory proteins in human endothelial cells. Arterioscler Thromb 1994;14:182936. 
158. Thanos D, Maniatis T. NF-kB: a lesson in family values. Cell 1995;80: 529-32.

159. Marui N, Offermann MK, Swerlick R, Kunsch C, Rosen CA, Ahmad M, Alexander RW, Medford RM. Vascular cell adhesion molecule (VCAM-1) gene transcription and expression are regulated through an antioxidant-sensitive mechanism in human vascular endothelial cells. J Clin Invest 1993;92:1866-74.

160. Hart CM, Gupta MP, Evanoff V. Oleic acid reduces oxidant stress in cultured pulmonary artery endothelial cells. Exp Lung Res 1997;23(5):405-25.

161. Karman RJ, Garcia JG, Hart CM. Endothelial cell monolayer dysfunction caused by oxidized low density lipoprotein: attenuation by oleic acid. Prostaglandins Leukot Essent Fatty Acids 1997;56(5):345-53.

162. Hart CM, Andreoli SP, Patterson CE, Garcia JG. Oleic acid supplementation reduces oxidant-mediated dysfunction of cultured porcine pulmonary artery endothelial cells. J Cell Physiol 1993;156(1):24-34.

163. Massaro M, Basta G, Lazzerini G, Carluccio MA, Bosetti F, Solaini G, Visioli F, Paolicchi A, De Caterina R. Quenching of intracellular ROS generation as a mechanism for oleate-induced reduction of endothelial activation and early atherogenesis. Thromb Haemost 2002;88(2):335-44.

164. Kwok CF, Shih KC, Hwu CM, Ho LT. Linoleic acid and oleic acid increase the endothelin-1 binding and action in cultured rat aortic smooth muscle cells. Metabolism 2000;49(11):1386-9.

165. Oram JF, Bornfeldt KE. Direct effects of long-chain non-esterified fatty acids on vascular cells and their relevance to macrovascular complications of diabetes. Front Biosci 2004;9:1240-53.

166. Tuck KL, Hayball PJ. Major phenolic compounds in olive oil: metabolism and health effects. J Nutr Biochem 2002;13(11):636-44.

167. Ohara Y, Peterson TE, Harrison DG. Hypercholesterolemia increases endothelial superoxide anion production. J Clin Invest 1993;91:2546-51.

168. Keaney JF Jr, Vita JA. Atherosclerosis, oxidative stress, and antioxidant protection in endothelium-derived relaxing factor action. Prog Cardiovasc Dis 1995;38:129-54.

169. Cai H, Harrison DG. Endothelial dysfunction in cardiovascular diseases: the role of oxidant stress. Circ Res 2000;87:840-4.

170. Heitzer T, Schlinzig T, Krohn K, Meinertz T, Munzel T. Endothelial dysfunction, oxidative stress, and risk of cardiovascular events in patients with coronary artery disease. Circulation 2001;104(22):2673-8.

171. Ting HH, Timimi FK, Haley EA, Roddy MA, Ganz P, Creager MA. Vitamin C improves endothelium-dependent vasodilation in forearm resistance vessels of humans with hypercholesterolemia. Circulation 1997;95(12):2617-22.

172. Levine GN, Frei B, Koulouris SN, Gerhard MD, Keaney JF Jr, Vita JA. Ascorbic acid reverses endothelial vasomotor dysfunction in patients with coronary artery disease. Circulation 1996;93(6):1107-13.

173. Heitzer T, Just $\mathrm{H}$, Munzel T. Antioxidant vitamin $\mathrm{C}$ improves endothelial dysfunction in chronic smokers. Circulation 1996;94:6-9. 
174. Jackson TS, Xu A, Vita JA, Keaney JF Jr. Ascorbate prevents the interaction of superoxide and nitric oxide only at very high physiological concentrations. Circ Res 1998;83(9):916-22.

175. Saija A, Trombetta D, Tomaino A, Lo Cascio R, Princi P, Ucella N, Bonina F, Castelli F. In vitro evaluation of the antioxidant activity and biomembrane interaction of the plant phenols oleuropein and hydroxy-tyrosol. Int J Pharmaceut 1998;166:123-33.

176. Gordon MH, Paiva-Martins F, Almeida M. Antioxidant activity of hydroxytyrosol acetate compared with that of other olive oil polyphenols. J Agric Food Chem 2001;49(5):2480-5.

177. Briante R, La Cara F, Tonziello MP, Febbraio F, Nucci R. Antioxidant activity of the main bioactive derivatives from oleuropein hydrolysis by hyperthermophilic betaglycosidase. J Agric Food Chem 2001;49(7):3198-203.

178. Tuck KL, Hayball PJ, Stupans I. Structural characterization of the metabolites of hydroxytyrosol, the principal phenolic component in olive oil, in rats. J Agric Food Chem 2002;50(8):2404-9.

179. Visioli F, Bellomo G, Galli C. Free radical-scavenging properties of olive oil polyphenols. Biochem Biophys Res Commun 1998;247(1):60-4.

180. Sutherland WH, de Jong SA, Walker RJ, Williams MJ, Murray Skeaff C, Duncan A, Harper M. Effect of meals rich in heated olive and safflower oils on oxidation of postprandial serum in healthy men. Atherosclerosis 2002;160(1):195-203.

181. Visioli F, Bellosta S, Galli C. Oleuropein, the bitter principle of olives, enhances nitric oxide production by mouse macrophages. Life Sci 1998;62(6):541-6.

182. Beckman JS, Koppenol WH. Nitric oxide, superoxide, and peroxynitrite: the good, the bad, and ugly. Am J Physiol 1996;271(5 Pt 1):C1424-C37.

183. de la Puerta R, Ruiz Gutierrez V, Hoult JR. Inhibition of leukocyte 5-lipoxygenase by phenolics from virgin olive oil. Biochem Pharmacol 1999;57(4):445-9.

184. Petroni A, Blasevich M, Salami M, Papini N, Montedoro GF, Galli C. Inhibition of platelet aggregation and eicosanoid production by phenolic components of olive oil. Thromb Res 1995;78(2):151-60.

185. Petroni A, Blasevich M, Papini N, Salami M, Sala A, Galli C. Inhibition of leukocyte leukotriene B4 production by an olive oil-derived phenol identified by massspectrometry. Thromb Res 1997;87(3):315-22.

186. Kohyama N, Nagata T, Fujimoto S, Sekiya K. Inhibition of arachidonate lipoxygenase activities by 2-(3,4-dihydroxyphenyl)ethanol, a phenolic compound from olives. Biosci Biotechnol Biochem 1997;61(2):347-50.

187. Petroni A, Blasevich M, Salami M, Servili M, Montedoro GF, Galli C. A phenolic antioxidant extracted from olive oil inhibits platelet aggregation and arachidonic acid metabolism in vitro. World Rev Nutr Diet 1994;75:169-72.

188. Miles EA, Zoubouli P, Calder PC. Differential anti-inflammatory effects of phenolic compounds from extra virgin olive oil identified in human whole blood cultures. Nutrition 2005;21(3):389-94.

189. Carluccio MA, Siculella L, Ancora MA, Massaro M, Scoditti E, Storelli C, Visioli F, Distante A, De Caterina R. Olive oil and red wine antioxidant polyphenols inhibit 
endothelial activation: antiatherogenic properties of Mediterranean diet phytochemicals. Arterioscler Thromb Vasc Biol 2003;23(4):622-9.

190. Ahmad M, Theofanidis $P$, Medford RM. Role of activating protein-1 in the regulation of the vascular cell adhesion molecule-1 gene expression by tumor necrosis factor-alpha. J Biol Chem 1998;273(8):4616-21.

191. Turner R, Etienne N, Alonso MG, de Pascual-Teresa S, Minihane AM, Weinberg PD, Rimbach G. Antioxidant and anti-atherogenic activities of olive oil phenolics. Int J Vitam Nutr Res 2005;75(1):61-70.

192. Ma Q, Kinneer K, Ye J, Chen BJ. Inhibition of nuclear factor kappaB by phenolic antioxidants: interplay between antioxidant signaling and inflammatory cytokine expression. Mol Pharmacol 2003;64(2):211-9.

193. Azzi A, Ricciarelli R, Zingg JM. Non-antioxidant molecular functions of alphatocopherol (vitamin E). FEBS Lett 2002;519(1-3):8-10.

194. de la Puerta R, Martinez-Dominguez E, Ruiz-Gutierrez V. Effect of minor components of virgin olive oil on topical antiinflammatory assays. Z Naturforsch [C] 2000;55(910):814-9.

195. Rodriguez-Rodriguez R, Herrera MD, Perona JS, Ruiz-Gutierrez V. Potential vasorelaxant effects of oleanolic acid and erythrodiol, two triterpenoids contained in 'orujo' olive oil, on rat aorta. Br J Nutr 2004;92(4):635-42.

196. Ochoa JJ, Quiles JL, Ramirez-Tortosa MC, Mataix J, Huertas JR. Dietary oils high in oleic acid but with different unsaponifiable fraction contents have different effects in fatty acid composition and peroxidation in rabbit LDL. Nutrition 2002;18(1):60-5.

197. Azzi A, Gysin R, Kempna P, Ricciarelli R, Villacorta L, Visarius T, Zingg JM. The role of alpha-tocopherol in preventing disease: from epidemiology to molecular events. Mol Aspects Med 2003;24(6):325-36.

198. Azzi A, Gysin R, Kempnà P, Ricciarelli R, Villacorta L, Visarius T, Zingg JM. Regulation of gene and protein expression by vitamin E. Free Radical Res 2002; 36:3036.

199. Jialal I, Fuller CJ, Huet BA. The effect of alpha-tocopherol supplementation on LDL oxidation. A dose-response study. Arterioscler Thromb Vasc Biol 1995;15(2):190-8.

200. Princen HM, van Duyvenvoorde W, Buytenhek R, van der Laarse A, van Poppel G, Gevers Leuven JA, van Hinsbergh VW. Supplementation with low doses of vitamin E protects LDL from lipid peroxidation in men and women. Arterioscler Thromb Vasc Biol 1995; 15(3):325-33.

201. Devaraj S, Adams-Huet B, Fuller CJ, Jialal I. Dose-response comparison of RRRtocopherol and all-racemic alpha-tocopherol on LDL oxidation. Arterioscler Thromb Vasc Biol 1997;17(10):2273-9.

202. Cominacini L, Garbin U, Cenci B, Davoli A, Pasini C, Ratti E, Gaviraghi G, Lo Cascio V, Pastorino AM. Predisposition to LDL oxidation during copper-catalyzed oxidative modification and its relation to alpha-tocopherol content in humans. Clin Chim Acta 1991;204(1-3):57-68.

203. Offermann MK, Medford RM. Antioxidants and atherosclerosis: a molecular perspective. Heart Dis Stroke 1994;3(1):52-7. 
204. Martin A, Foxall T, Blumberg JB, Meydani M. Vitamin E inhibits low-density lipoprotein-induced adhesion of monocytes to human aortic endothelial cells in vitro. Arterioscler Thromb Vasc Biol 1997;17(3):429-36.

205. Zapolska-Downar D, Zapolski-Downar A, Markiewski M, Ciechanowicz A, Kaczmarczyk M, Naruszewicz M. Selective inhibition by alpha-tocopherol of vascular cell adhesion molecule-1 expression in human vascular endothelial cells. Biochem Biophys Res Commun 2000;274(3):609-15.

206. Faruqi R, de la Motte C, DiCorleto PE-tocopherol inhibits agonist-induced monocytic cell adhesion to cultured human endothelial cells. J Clin Invest 1994;94(2):592-600.

207. Yoshikawa T, Yoshida N, Manabe H, Terasawa Y, Takemura T, Kondo M. $\quad \alpha$ tocopherol protects against expression of adhesion molecules on neutrophils and endothelial cells. Biofactors 1998;7(1-2):15-9.

208. Akeson AL, Woods CW, Mosher LB, Thomas CE, Jackson RL. Inhibition of IL-1 beta expression in THP-1 cells by probucol and tocopherol. Atherosclerosis 1991;86(23):261-70.

209. Okuma M, Takayama H, Uchino H. Generation of prostacyclin-like substance and lipid peroxidation in vitamin E-deficient rats. Prostaglandins 1980;19(4):527-36.

210. Chan AC, Leith MK. Decreased prostacyclin synthesis in vitamin E-deficient rabbit aorta. Am J Clin Nutr 1981;34(11):2341-7.

211. Kunisaki M, Umeda F, Inoguchi T, Nawata H. Vitamin E binds to specific binding sites and enhances prostacyclin production by cultured aortic endothelial cells. Thromb Haemost 1992;68(6):744-51.

212. Kunisaki M, Umeda F, Inoguchi T, Nawata H. Vitamin E restores reduced prostacyclin synthesis in aortic endothelial cells cultured with a high concentration of glucose. Metabolism 1992;41(6):613-21.

213. Jialal I, Devaraj S, Kaul N. The effect of alpha-tocopherol on monocyte proatherogenic activity. J Nutr 2001;131(2):389S-94S.

214. Wu D, Hayek MG, Meydani SN. Vitamin E and macrophage cyclooxygenase regulation in the aged J. Nutr 2001;131:382S-8S.

215. Meydani SN, Meydani M, Verdon CP, Shapiro AA, Blumberg JB, Hayes KC. Vitamin E supplementation suppresses prostaglandin E1(2) synthesis and enhances the immune response of aged mice. Mech Ageing Dev 1986;34(2):191-201.

216. Meydani SN, Lipman R, Blumberg JB, Taylor A. Dietary energy restriction decreases ex vivo spleen prostaglandin E2 synthesis in Emory mice. J Nutr 1990;120(1):112-5.

217. Meydani SN, Shapiro AC, Meydani M, Blumberg JB. Lung eicosanoid synthesis is affected by age, dietary fat and vitamin E. J Nutr 1992;122(8):1627-33.

218. Kim JY, Lee KH, Lee BK, Ro JY. Peroxynitrite modulates release of inflammatory mediators from guinea pig lung mast cells activated by antigen-antibody reaction. Int Arch Allergy Immunol 2005;137(2):104-14.

219. Hennig B, Boissonneault GA, Chow CK, Wang Y, Matulionis DH, Glauert HP. Effect of vitamin $\mathrm{E}$ on linoleic acid-mediated induction of peroxisomal enzymes in cultured porcine endothelial cells. J Nutr 1990;120(4):331-7. 
220. Li D, Saldeen T, Mehta JL. Effects of alpha-tocopherol on ox-LDL-mediated degradation of IkappaB and apoptosis in cultured human coronary artery endothelial cells. J Cardiovasc Pharmacol 2000;36(3):297-301.

221. Fazzio A, Marilley D, Azzi A. The effect of alpha-tocopherol and beta-tocopherol on proliferation, protein kinase $C$ activity and gene expression in different cell lines. Biochem Mol Biol Int 1997;41(1):93-101.

222. Breyer I, Azzi A. Differential inhibition by alpha- and beta-tocopherol of human erythroleukemia cell adhesion: role of integrins. Free Radic Biol Med 2001;30(12):1381-9.

223. Weber C, Erl W, Pietsch A, Weber PC. Aspirin inhibits NF-kB mobilization and monocyte adhesion in stimulated human endothelial cells. Circulation 1995;91:1914-17.

224. Neuzil J, Svensson I, Weber T, Weber C, Brunk UT. Tocopheryl succinate-induced apoptosis in Jurkat T cells involves caspase-3 activation and both lysosomal and mitochondrial destabilisation. FEBS Lett 1999;445:295-300.

225. Neuzil J, Weber T, Gellert N, Weber C. Selective cancer cell killing by $\alpha$-tocopheryl succinate, Br J Cancer 2001;84:87-9.

226. Christen S, Woodall AA, Shigenaga MK, Southwell-Keely PT, Duncan MW, Ames BN. gamma-tocopherol traps mutagenic electrophiles such as $\mathrm{NO}(\mathrm{X})$ and complements alpha-tocopherol: physiological implications. Proc Natl Acad Sci USA 1997;94(7):3217-22.

227. Jones PJ, MacDougall DE, Ntanios F, Vanstone CA. Dietary phytosterols as cholesterollowering agents in humans. Can J Physiol Pharmacol 1997;75(3):217-27.

228. Vanstone CA, Raeini-Sarjaz M, Jones PJ. Injected phytosterols/stanols suppress plasma cholesterol levels in hamsters. J Nutr Biochem 2001;12(10):565-74.

229. Quilez J, García-Lorda P, Salas-Salvado J. Potential uses and benefits of phytosterols in diet: present situation and future directions. Clin Nutr 2003;22(4):343-51. Review.

230. Ho SS, Pal S. Margarine phytosterols decrease the secretion of atherogenic lipoproteins from HepG2 liver and Caco2 intestinal cells. Atherosclerosis 2005;182(1):29-36.

231. de Jongh S, Vissers MN, Rol P, Bakker HD, Kastelein JJ, Stroes ES. Plant sterols lower LDL cholesterol without improving endothelial function in prepubertal children with familial hypercholesterolaemia. J Inherit Metab Dis 2003;26(4):343-51.

232. Moreno J. Effect of olive oil minor components on oxidative stress and arachidonic acid mobilization and metabolism by macrophages RAW 264.7. Free Radic Biol Med 2003;35(9):1073-81.

233. Cert A, Moreda W, Garcia-Moreno J. Determination of sterols and triterpenic dialcohols in olive oils using HPLC separation and GC analysis. Standardization of the analytical method. Grasas aceites 1997;48 (4): 207-218.

234. Liu J. Pharmacology of oleanolic acid and ursolic acid. J Ethnopharmacol 1995;49(2):57-68.

235. Herrera MD, Rodriguez-Rodriguez R, Ruiz-Gutierrez V. Functional properties of pentacyclic triterpenes contained in "orujo" olive oil. Curr Nutr Food Sci (in press). 
236. Simon A, Najid A, Chulia AJ, Delage C, Rigaud M. Inhibition of lipoxygenase activity and HL60 leukemic cell proliferation by ursolic acid isolated from heather flowers (Calluna vulgaris). Biochim Biophys Acta 1992;1125(1):68-72.

237. Ringbom T, Segura L, Noreen Y, Perera P, Bohlin L. Ursolic acid from Plantago major, a selective inhibitor of cyclooxygenase-2 catalyzed prostaglandin biosynthesis. J Nat Prod 1998;61(10):1212-5.

238. Leu YL, Kuo SM, Hwang TL, Chiu ST. The inhibition of superoxide anion generation by neutrophils from Viscum articulactum. Chem Pharm Bull (Tokyo) 2004;52(7):85860. 
Table 1. Minor Component Composition of Virgin Olive Oil.

\begin{tabular}{|c|c|c|}
\hline \multicolumn{2}{|c|}{ Sub-fraction Component } & $\begin{array}{c}\text { Concentration } \\
(\mathrm{mg} / \mathrm{kg})\end{array}$ \\
\hline \multicolumn{3}{|l|}{ UNSAPONIFIABLE } \\
\hline Hydrocarbons & $\begin{array}{l}\text { Squalene } \\
\beta \text {-Carotene } \\
\text { Polycyclic aromatic hy }\end{array}$ & $\begin{array}{l}200-7500 \\
0.3-0.7 \\
\text { nTsaces }\end{array}$ \\
\hline Sterols & $\begin{array}{l}\beta \text {-Sytosterol } \\
\text { Campesterol } \\
\Delta 7 \text {-Stigmasterol } \\
\text { Brassicasterol }\end{array}$ & $\begin{array}{l}1800-2600 \\
<4.0 \% \text { of total sterols } \\
<0.5 \% \text { of total sterols } \\
<0.1 \% \text { of total sterols }\end{array}$ \\
\hline Terpenic Dialcohols & Erythrodyol + Uvaol & $6-10+18$ \\
\hline Tocopherols & $\begin{array}{l}\alpha \text {-Tocopherol } \\
\beta+\gamma \text {-Tocopherol } \\
\Delta \text {-Tocopherol }\end{array}$ & $\begin{array}{l}60-200 \\
3 \% \text { of total tocopherols } \\
<2 \% \text { of total tocopherols }\end{array}$ \\
\hline $\begin{array}{l}\text { PHENOLIC } \\
\text { COMPOUNDS }\end{array}$ & $\begin{array}{l}\text { Tyrosol } \\
\text { Hydroxytyrosol } \\
\text { Caffeic acid } \\
\text { Oleuropein }\end{array}$ & 50-800 (total phenols) \\
\hline OTHERS & Flavour components & Traces \\
\hline
\end{tabular}


Figure 1. Proposed model for the action mechanisms of the oleic acid and minor compounds from olive oil based on the literature gathered for the present review. Despite the number of studies contributing to this model several gaps are still present, which should be filled with further investigations. The main mechanism by which the components of olive oil influence endothelial activation involves inhibition and/or scavenging of reactive oxygen species (ROS). Oleic acid and $\beta$-sitosterol may reduce intracellular ROS by creating a less oxidant environment through inhibition of intracellular ROS production. $\beta$-sitosterol may also enhance superoxide dismutase (SOD) activity, hence decreasing superoxide 2 intogel $\mid \$ O$ This reduction has also been observed for the terpenoid oleanolic acid, although the mechanism is not presently known. Tocopherols and phenolic compounds are potent antioxidants that may help to reduce lipid peroxidation and to scavenge intracellular ROS and free radical nitric oxide (NO, reducing the formation of peroxynitrite (OON)OROS can activate the nuclear factoB ( $N F \kappa B$ ), which is then translocated into the nucleus, where it binds to recognition sequences in DNA in order to induce gene expression. This mobilisation of NF KB is blocked byo-tocopheryl succinate but not doytocopherol. In contrast, phenolic compounds have been proposed to act blocking the formation of NאB/DNA binding complexes. NFKB modulates the expression of cytokines, 5-lipooxygenase (LOX) and cyclooxygenase (COX), thereby affecting the levels of adhesion molecules and eicosanoids. However, some of the minor compounds of olive oil may act directly on these enzymes and cytokines. LOX and COX activities are inhibited at different points by phenolics and triterpenoids and IL-1 expression by phenolics and tocopherols, contributing to protect the endothelium against vasoconstriction, platelet aggregation and monocyte adhesion. Vasodilation is also suggested to be enhanced by oleuropein and oleanolic acid through increase of the production of nitric oxide (NO).

Figure 2. Effect of the unsaponifiable fraction of olive oil in TRLS on eicosanoid production. HUVEC were incubated for ( $24 \mathrm{~h}$ ) with TRL obtained $2 \mathrm{~h}$ after the ingestion of high-oleic sunflower (HOSO), virgin olive (VOO) or enriched-virgin olive (EVO) oils. Eicosanoid released to the medium were determined by ElAs. Results corresponding 2 tđREE Eand 6 -keto-PGF $F_{1 \alpha}$ are shown in panels $A, B$ and $C$ respectively. $a: p<0.05$, vs. Control; $b$ : $p<0.05$, vs. HOSO; c: $p<0.05$, vs. VOO.

Figure 3. Relaxant effect of oleanolic acid (A) and erythrodiol (B) in phenylephriñ precontracted rat aortic rings. Addition of the NO-synthase inhibitor L-NAME (3xing) produced a significant reduction of the endothelium-dependent relaxation to both triterpenic compounds (circles) compared to control (squares). ${ }^{* * *}$ : $p<0.001$, vs. Control. 


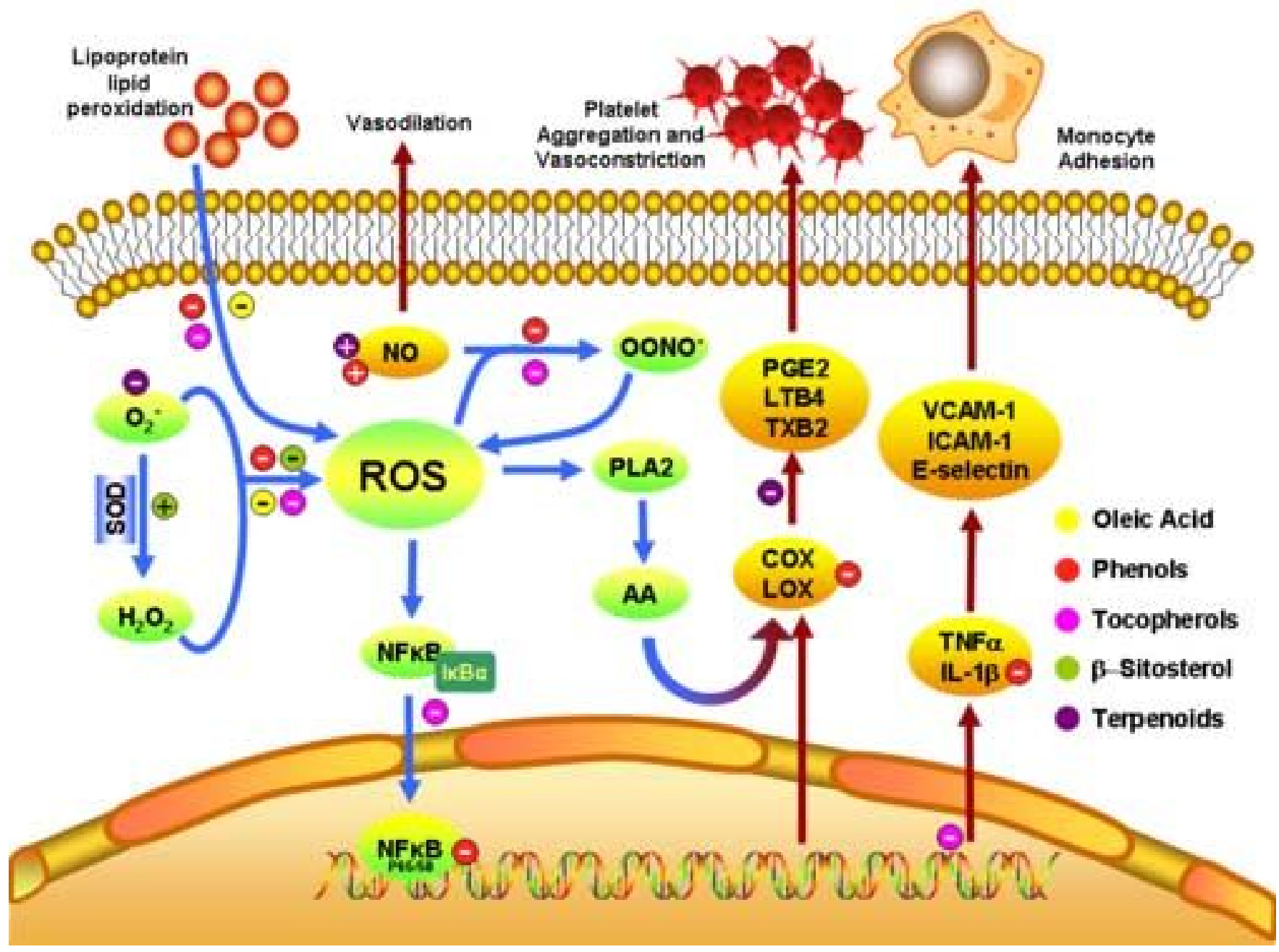


Click here to download high resolution image
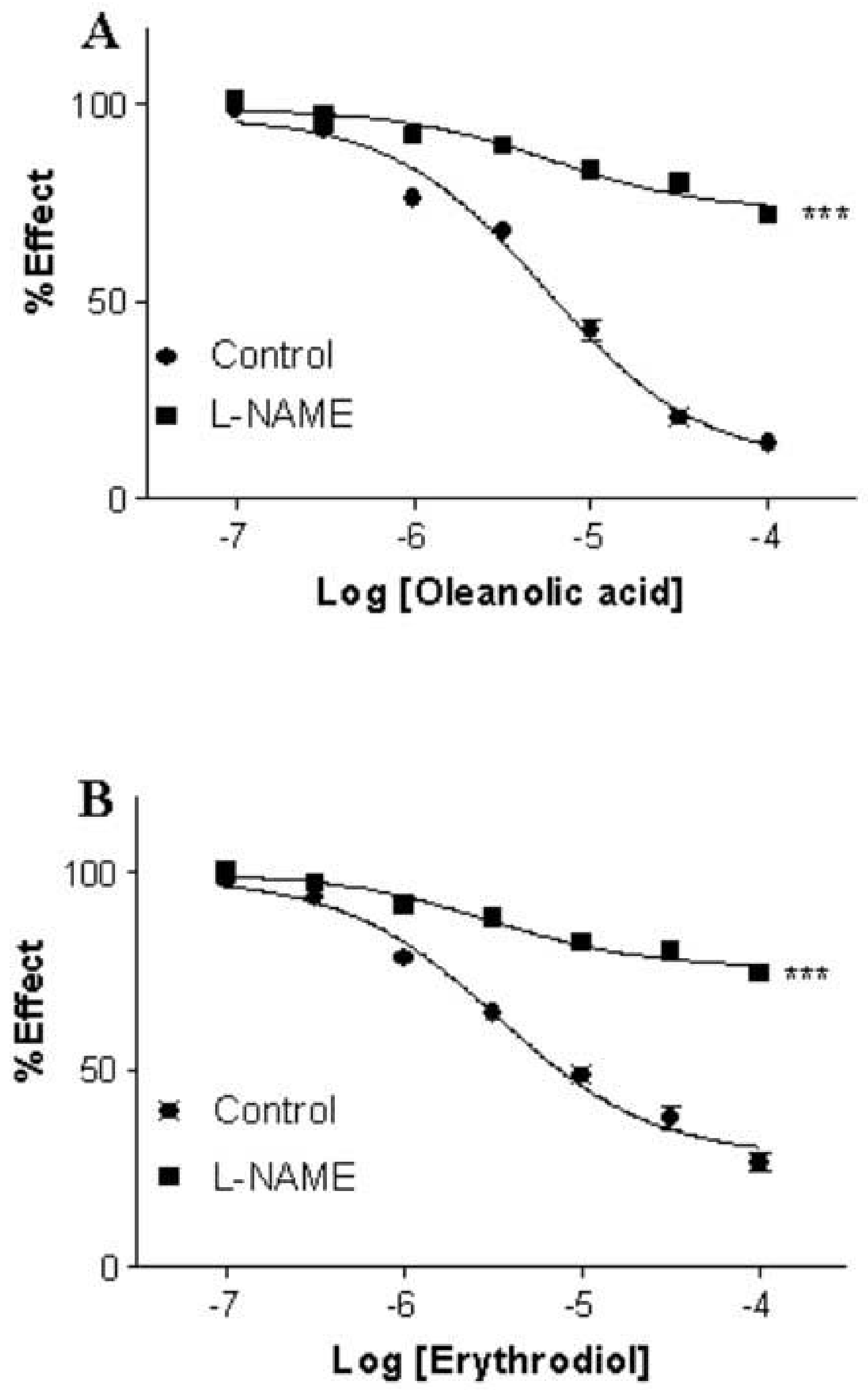
Click here to download high resolution image
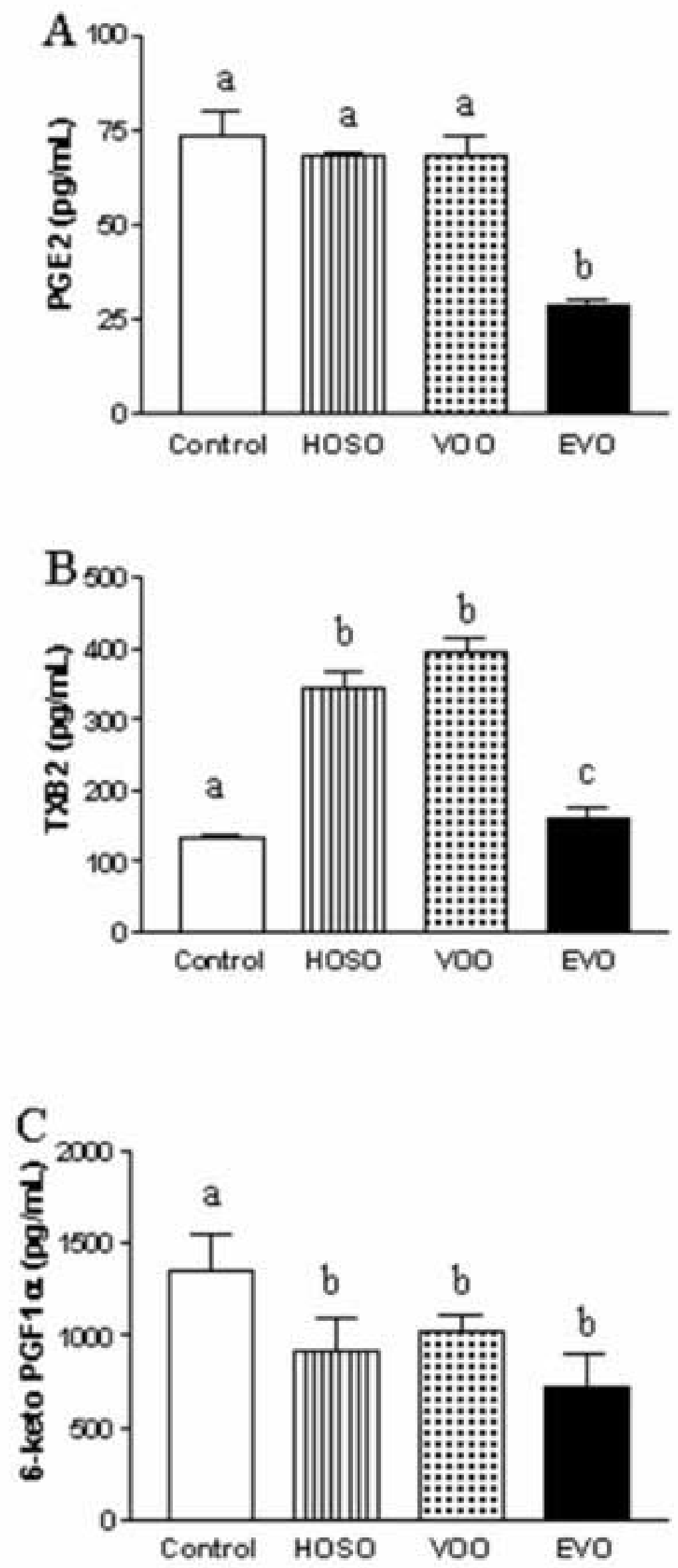